\title{
Recent Changes in Temperature Extremes in Subtropical Climate Region and the Role of Large- Scale Atmospheric Oscillation Patterns
}

Javed Mallick

King Khalid University

Roquia Salam

Begum Rokeya University

H. M. Touhidul Islam

Begum Rokeya University

Shamsuddin Shahid

Universiti Teknologi Malaysia (UTM)

Mohammad Kamruzzaman

Gyeongsang National University

\section{Subodh Chandra Pal}

The University of Burdwan

Shakeel Ahmad Bhat

SKUAST- Kashmir

Ahmed Elbeltagi

Mansoura University

Thiago Rangel Rodrigues

Universidade Federal de Mato Grosso do Sul

Sobhy M. Ibrahim

King Saud University

Abu Reza Md. Towfiqul Islam ( $\square$ towfiq_dm@brur.ac.bd)

Begum Rokeya University https://orcid.org/0000-0001-5779-1382

\section{Research Article}

Keywords: Extreme temperature indices, ENSO teleconnction, Elevations, SST, Atmospheric circulation, Bangladesh

Posted Date: October 25th, 2021

DOI: https://doi.org/10.21203/rs.3.rs-932938/v1 
License: (c) (i) This work is licensed under a Creative Commons Attribution 4.0 International License. Read Full License

Version of Record: A version of this preprint was published at Theoretical and Applied Climatology on January 27th, 2022. See the published version at https://doi.org/10.1007/s00704-021-03914-4. 


\section{Recent changes in temperature extremes in subtropical climate region and} the role of large-scale atmospheric oscillation patterns

Javed Mallick ${ }^{1 *}$, Roquia Salam ${ }^{2}$, H. M. Touhidul Islam², Shamsuddin Shahid ${ }^{3}$, Mohammad Kamruzzaman ${ }^{4,5, * * *}$, Subodh Chandra $\mathrm{Pal}^{6}$, Shakeel Ahmad Bhat ${ }^{7}$, Ahmed Elbeltagi ${ }^{8}$, Thiago Rangel Rodrigues $^{9}$, Sobhy M. Ibrahim ${ }^{10}$, Abu Reza Md. Towfiqul Islam ${ }^{2 * *}$

${ }^{1}$ Department of Civil Engineering, King Khalid University, Abha, Saudi Arabia

${ }^{2}$ Department of Disaster Management, Begum Rokeya University, Rangpur-5400, Bangladesh

${ }^{3}$ Department of Water \& Environmental Engineering, School of Civil Engineering, Universiti Teknologi Malaysia (UTM), 81310 Johor, Malaysia

${ }^{4}$ Department of Agricultural Engineering, Institute of Agriculture and Life Science, Gyeongsang National University, Jinju-daero 501, Jinju, Gyeongnam 52828, Republic of Korea

${ }^{5}$ Farm Machinery and Postharvest Technology Division, Bangladesh Rice Research Institute, Gazipur 1701, Bangladesh

${ }^{6}$ Department of Geography, The University of Burdwan, Bardhaman-713104, West Bengal, India ${ }^{7}$ College of Agricultural Engineering and Technology, SKUAST- Kashmir, Srinagar-190025

${ }^{8}$ Agricultural Engineering Dept., Faculty of Agriculture, Mansoura University, Mansoura 35516, Egypt

${ }^{9}$ Laboratório de Ciências Atmosféricas, Universidade Federal de Mato Grosso do Sul, Campo Grande, MS 79070-900, Brazil

${ }^{10}$ Department of Biochemistry, College of Science, King Saud University, P.O. Box: 2455, Riyadh 11451, Saudi Arabia

"Corresponding author: towfiq_dm@brur.ac.bd; jmallick@kku.edu.sa; milonbrri@gmail.com

Abu Reza Md Towfiqul Islam, PhD

ORCID: 0000-0001-5779-1382

Javed Mallick, PhD

Mohammad Kamruzzaman, PhD 
Understanding the recent variations in temperature extremes is crucial to anticipate the forthcoming incidences of extreme phenomena. However, Knowledge on temperature extremes' spatial and temporal patterns, as well as their links to atmospheric oscillation and topography, is scarce in Bangladesh. To this end, this research intends to analyze the spatial and temporal trends in recent extreme temperatures and their relationships with oscillation indices and the topography of Bangladesh. Daily temperature data obtained from 20 meteorological stations for 1980-2017 were employed for this purpose. Results revealed that the rises in summer days (SU25), tropical nights (TR20), warm days (TX90p), warmest days (TXx) and warm nights (TN90p), while declinations in coldest days (TNn), cold days (TX10p) and cold nights (TN10p) in Bangladesh. Spatial distribution of trends revealed an increase in SU25 and TN90p by 1.9-2.38, 2.33-2.90 days/decade, and a decrease in TX10p and TN10p by 1.7-3.3 days/decade in most regions. Besides, TR20 showed an increase of 3.22-4.17 days/decade in all sub-regions. The temperature extremes of Bangladesh showed a significant connection with multivariate ENSO index (MEI) and Sea Surface Temperature (SST). Besides, the extremes in most regions of the country showed a significant connection with Southern Oscillation Index (SOI) and Indian Ocean Dipole (IOD). The influence of atmospheric oscillation indices was more evident on cold days/nights than on warm days/nights. TN10p and SU25 also showed a significant correlation with elevation, suggesting an increase in cold night and summer day temperature with the increase in elevation in Bangladesh. Large-scale climate mode reanalysis revealed that a strong (weak) wind speed, enhancing (decreasing) geopotential height, and fast warming (cooling) over the northwestern (southeast) region have attributed to the variations in extreme temperature in Bangladesh to several extents. Climate change adaptation and disaster mitigation in Bangladesh will benefit from these findings.

Keywords: Extreme temperature indices, ENSO teleconnction, Elevations, SST, Atmospheric circulation, Bangladesh 


\section{Introduction}

60

61

62

The global mean surface temperature increased by $0.74^{\circ} \mathrm{C}$ during the previous century and is predicted to climb by $1.84^{\circ} \mathrm{C}$ by the end of this one (IPCC 2014). Only a slight shift in the mean temperature results from significant variations in the frequency of temperature extremes (Hansen et al., 1988; Khan et al. 2020). As a result of global warming, temperature extremes are already increasing over the world. Therefore, the scientific community is more concerned about increasing climate extremes because of higher societal vulnerability to climatic extremes than the accumulated mean climate (Katz and Brown, 1992). Numerous studies reported variations in intensity, frequency, regional extent, length, and timing of temperature extremes and their implications for agricultural practices and human mortality (Piao et al. 2010; Dey et al. 2021). Widespread increases in temperature extremes are anticipated to remain owing to global warming, making them a key policy concern for governments, the general people, and the climate research scientists (Almazroui et al., 2014; Durre et al., 2000; Sun et al., 2014; Viola et al., 2014; Khan et al. 2019; Das 2021).

Bangladesh is one of the top ten nations most susceptible to climatic change in the world (Rahman and Islam 2019; Eckstein et al. 2017; Das and Islam 2021). Increased daily temperatures and temperature-related extreme phenomena are the most substantial effect of climate change in the country, as they are elsewhere in the world (Shahid et al., 2016). Temperature extremes have severe consequences for agriculture (Sikder et al. 2014), ecosystem (Islam et al., 2021a), and other sectors in the country (Shahid et al., 2016). Temperature variability is most likely to reduce agricultural yields in Bangladesh (Islam et al., 2011). Plant development, pollination, and reproductive processes are all affected by higher temperatures (Sacks and Kucharik, 2011; Klein Tank et al., 2006). Even short term extreme high and low temperatures can decline the growth and productivity of crops (Mearns et al., 1984). Due to extreme temperature variability, total rice production in Bangladesh may 
decrease by $7.4 \%$ per year in the future (Sarker et al., 2012). Therefore, it is vital to estimate changes in the mean temperature sequence and the frequency, magnitude, and extent of extreme temperature occurrences (Alexander et al., 2006; Easterling et al., 2000; Moberg and Jones, 2005). However, the features of the extreme climate-related phenomenon at the regional level in Bangladesh are little understood. So, it is essential to monitor changes in temperature extremes in Bangladesh frequently.

In recent time, Bangladesh has experienced a colder winter with a significant increase in the low temperature and a hotter summer (Nishat and Mukherjee, 2013). The monthly mean temperature increased at more than a few agro-ecological zones both on a seasonal and annual scale (Mia, 2003). The monthly maximum temperature showed an increasing trend, while the monthly minimum temperature fluctuated between rising and falling (Islam et al., 2020a). Earlier research solely looked at monthly and annual minimum and maximum trends to assess extreme changes. The Expert Team on Climate Change Detection and Indices (ETCCDI) has been extensively employed in climate change studies all around the globe to identify extreme temperature indices that better represent temperature extremes (Zhang et al., 2011). However, these indices are used by very few scholars for studying on Bangladesh context to date. Previous studies also mainly focused on either the shift in mean value or the changes in pattern (Kamruzzaman et al. 2019a; Nowreen et al. 2012; SMRC 2009; Shahid 2009; Abdullah et al, 2020; Islam et al., 2021b). The temporal distribution of six threshold temperature indices of Bangladesh and its associated effects on several fields have been assessed by Shahid et al. (2016). However, the results presented in their study were not sufficient to understand the variations in regional temperature extremes. It is possible to describe temperature-related climate extremes in Bangladesh better using the broad range of extreme temperature indices defined in ETCCDI. 
Large-scale atmospheric circulations directly impact local climate fluctuations at both shortterm and long-term climate time scales. An insight into their connections with temperature extremes can better inform the drivers of temperature extremes (Ghose et al., 2021a, b). A few studies investigated the relationship of large-scale atmospheric circulations to temperature and precipitation over the country. According to Wahiduzzaman and Luo (2020), the El Nino-Southern Oscillation (ENSO) affects the temperature and precipitation in Bangladesh .The relationship varies depending on the location and season. However, so far, no research has been conducted on the temporal and spatial trends of the connection of extreme temperature phenomena to the large-scale climatic indices in Bangladesh. The current study aims to analyze the changes in Bangladesh's ETCCDI extreme temperature indices between 1980 and 2017 and the links between the extremes and atmospheric oscillation indices and the country's geography, taking into account the gaps in prior work. The novelty of this work is that the trends of extreme temperature indices and thier connections to large-scale climate indices were analyzed in Bangladesh for the first time on a regional scale to understand their spatial and temporal variability. This research may be used for climate change mitigation and adaptation planning, as well as for establishing an early warning system.

\section{Data and Methods}

\subsection{Study area description}

Bangladesh is a low-lying subtropical nation in South Asia, with latitudes ranging from $20^{\circ} 34 \mathrm{~N}$ to $26^{\circ} 38 \mathrm{~N}$ and longitudes varied from $88^{\circ} 01 \mathrm{E}$ to $92^{\circ} 41 \mathrm{E}$. Except for few hilly regions in the southeastern and eastern portions, the country's entire area is 147,570 $\mathrm{km} 2$, with flood plains covering its majority. Seasonal variation in rainfall and temperature are indistinguishable characteristics of its climate. The country's climate is characterized by a hot and humid summer with heavy rain and a dry and mildly cold 
winter. The four major seasons in the nation are winter (December to February), premonsoon (March to May), monsoon (June to September), and post-monsoon (October to November) (Kamruzzaman et al., 2019b). Bangladesh has an average daily mean relative humidity of $80 \%$ and evapotranspiration of $3.72 \mathrm{~mm}$ per day, respectively (Salam and 137 Islam, 2020). The coldest January and hottest months in Bangladesh between April and 138 October. The maximum rainfall occurs in the northeastern Sylhet district (Banglapedia, 2014). The present study divided the whole of Bangladesh into three regions as Northern 140 (Region 1), Southern (Region 2), and Central (Region 3) according to its geographical 141 location, hydrological settings, climatic variation, and soil type (Banglapedia 2014). The 142 northern region consists of the districts of Bogura, Rajshahi, Rangpur, Mymensingh and 143 Sylhet. The southern part consists of Cox's Bazar, Rangamati, Sandwip, Barishal, Bhola, 144 Feni, Khulna, Patuakhali, Sitakundu, and Teknaf. The central region covers Jashore, 


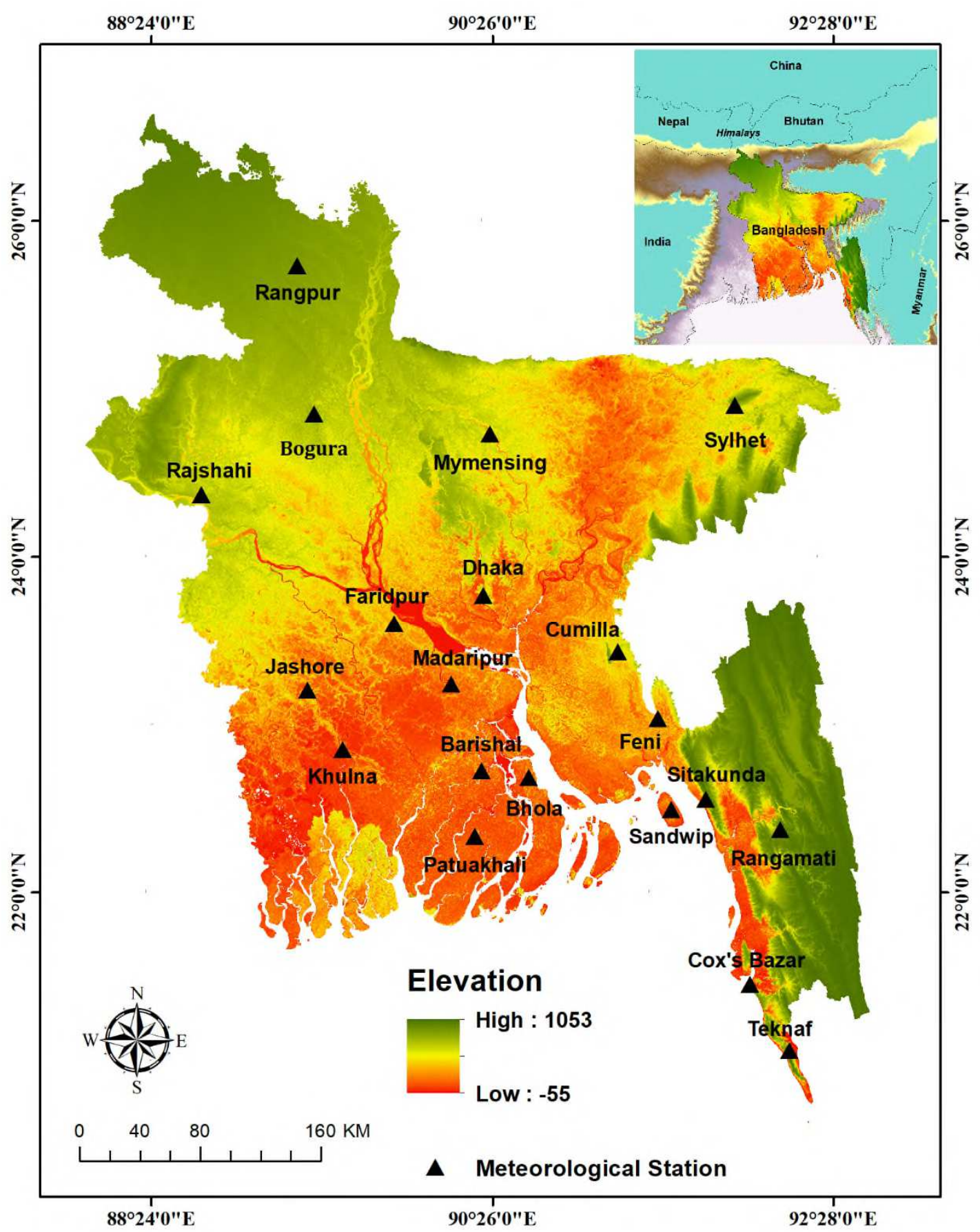

147 Figure 1 The location of Bangladesh, as well as its elevation spatial distributions and 148 meteorological station locations.

\section{$149 \quad 2.2$ Data sources and quality control check}

150 There are 43 meteorological sites in the Bangladesh Meteorological Department (BMD) 151 distributed homogeneously across the country. However, most of them start operating after 
1990 (Jerin et al. 2021). The availability of a longer period dataset, the amount of missing documents, and the spatial distribution of the stations were used to secure the records from these 43 stations. Because several stations were built after 1990, long-term data was not accessible. Furthermore, at certain sites, a missing climate record was discovered at a very high level. As a result, only 20 locations with data dating back to 1980 and covering the whole country were used in this study. The daily maximum and minimum temperatures datasets obtained at those 20 locations from 1980 to 2017 were used to reflect the country's climate uniformly, with missing values less than $4 \%$ and geographical distribution.

Missing data at each site was supplemented by data from neighboring sites. In addition, the stations that were eliminated owing to a lack of data for a longer period of time were used to fill in the gaps. Supplementary Tables S1 and S2 provide further details on the filling-in of missing datasets. The BMD recorded and collected meteorological data in accordance with the World Meteorological Organization's (WMO) criteria. However, before examining climate extremes, quality control of the dataset is still necessary since erroneous outliers have a substantial impact on the extremes (Gao et al., 2015).

First, station observations were checked for quality by systematic means, such as looking for positive records of climatic variables like Tmin being lower than Tmax and temperatures being below $45^{\circ} \mathrm{C}$. In addition, the SNHT (Standard Normal Homogeneity Test) at a significance threshold of $\mathrm{p}<0.05$ was carried out at all sites to show any irregularities in the datasets (Islam et al., 2020b). The time-series data were found to be homogeneous and consistent at all locations (Hans, 1986). All data records were authorized by the BMD staff after a quality check was performed on them. One of the most difficult issues in trend analysis is serial autocorrelation (Praveen et al., 2020). Only a few instances of serial autocorrelation in time series were found to have a $\mathrm{p}$ value of 0.05 or higher. 
176 Extreme climate indices were calculated from daily data using Rclimdex, a specially built and

177 publicly available software. ETCCDMI (Expert Team on Climate Change Detection, Monitoring, and

178 Indices) produced this software, which can be obtained from the ETCCDI website

179 (http://etccdi.pacificclimate.org/software.shtml). The ETCCDI has developed a set of 27 core climate

180 indices, including 16 temperature indices that are mainly related with extreme events. Considering the climatology of this region eight core temperature indices were examined in this study: warm days (TX90p), warm night (TN90p), cold days (TX10p), cold nights (TN10p), hottest days (TXx), coldest days (TNn), summer days (SU25), and tropical night (TR20). Table 1 presents a detailed description of these eight indices.

Five climatic indices of the atmospheric and oceanic circulation patterns and the elevation of the respective stations were used to analyze their possible connections with temperature extremes. These indices include North Atlantic Oscillation (NAO), Multivariate ENSO Index (MEI), Indian Ocean Dipole (IOD), Southern Oscillation Index (SOI), and Sea Surface Temperature (SST). Monthly values of SST, IOD, NAO, MEI, and SOI were derived from the National Oceanic and Atmospheric Association (NOAA) Climate Prediction Center (CPC) (www.cpc.ncep.noaa.gov) during the period 1980-2017.

Table 1: Selected temperature extrmes indices for this study

\begin{tabular}{|c|c|c|c|}
\hline No. & Indicator & Definition & Unit \\
\hline 1 & SU25 (Summer days) & Annual count when TX (daily maximum) $>25^{\circ} \mathrm{C}$ & Days \\
\hline 2 & TR20 (Tropical nights) & Annual count when $\mathrm{TN}$ (daily minimum) $>20^{\circ} \mathrm{C}$ & Days \\
\hline 3 & TXx (Warmest days) & $\begin{array}{l}\text { Monthly maximum value of daily maximum } \\
\text { temperature }\end{array}$ & ${ }^{\circ} \mathrm{C}$ \\
\hline 4 & TNn (Coldest days) & $\begin{array}{l}\text { Monthly minimum value of daily minimum } \\
\text { temperature }\end{array}$ & ${ }^{\circ} \mathrm{C}$ \\
\hline 5 & TN10p (Cold nights) & Percentage of days when $\mathrm{TN}<10$ th percentile & Days \\
\hline 6 & TX10p (Cold days) & Percentage of days when TX $<10$ th percentile & Days \\
\hline 7 & TN90p (Warm nights) & Percentage of days when $\mathrm{TN}>90$ th percentile & Days \\
\hline 8 & TX90p (Warm days) & Percentage of days when TX >90th percentile & Days \\
\hline
\end{tabular}


204

207

208

209

210

211

212

\subsection{Mann-Kendall test}

Temperature extremes follow a nonlinear behaviour (Shahid et al., 2016; Praveen et al., 2020; Islam et al., 2021; Kamruzzaman et al. 2019b). Thus, a nonparametric test named the MannKendall (MK) test has adopted to explore the trend of the temperature extremes (Kendall 1975; Mann 1945; Ullah et al. 2018; Islam et al. 2020a, Kamruzzaman et al. 2019b). It is widely utilized because to its robust characteristics and minimal sensitivity to rapid changes. (Li et al., 2018). The Mann-Kendall statistic (S) is calculated as follows:

$S=\sum_{k=1}^{n-1} \sum_{j=k+1}^{n} \operatorname{sign}\left(x_{j}-x_{k}\right)$

\section{Where}

$\operatorname{sign}\left(x_{j}-x_{k}\right)=\left\{\begin{array}{c}1 \text { if }\left(x_{j}-x_{k}\right)>0 \\ 0 \text { if }\left(x_{j}-x_{k}\right)=0 \\ -1 \text { if }\left(x_{j}-x_{k}\right)<0\end{array}\right.$

The probability related to $\mathrm{S}$ for sample size, $\mathrm{n}$, is calculated to measure the significance of the trend statistically. Normalized test statistic $\mathrm{Z}$ is computed as follows:

$Z=\left\{\begin{array}{l}\frac{S-1}{\sqrt{\operatorname{VAR}(S)}} \text { if } S>0 \\ 0 \quad \text { if } S=0 \\ \frac{S-1}{\sqrt{\operatorname{VAS}(S)}} \text { if } S<0\end{array}\right.$

If $|\mathrm{Z}|$ is higher than or equal to $2.575,1.96$, or 1.645 , the null hypothesis of no trend is rejected at the $99 \%, 95 \%$ and $90 \%$ significance levels, respectively. To get the sequential form of the MK test, the number $n_{i}$ of lower elements $x_{j}\left(x_{j<} x_{i}\right)$ preceding it $(j<i)$ for each element $x_{i}(i=1 \ldots \ldots . n)$ of the series is calculated.

The test statistics $t$ is given by

$t=\sum_{i} n$

In the lack of any trend (null hypothesis), $\mathrm{t}$ is asymptotically normal data distribution $u(t)=[t-E(t)] / \operatorname{var}^{2}(t)$ 
217 It has a normally distributed, with an expected value $\mathrm{E}(\mathrm{t})$ and variance $\operatorname{var}^{2}(\mathrm{t})$ stated by,

and

$\operatorname{var}^{2}(t)=n(n-1)(2 n+5) / 72$

The null hypothesis can, thus, be rejected for elevated values of $|\mathrm{u}(\mathrm{t})|$

There is a possibility that serial autocorrelation influences trend patterns, with positive autocorrelation pointing to an increased number of false-positive MMK test results (Ullah et al., 2018). This is why the serial autocorrelation was eliminated prior to implementing the MMK test (Islam et al., 2020b). To reduce autocorrelation, the TFPW (trend free prewhitening) technique was used in this study (Li et al., 2018). Besides, the sequential form of the MK test comprises of the test, commencing from the first term and finishing in the i-th term, then in those beginning in the i-th term and terminating in the last term (regressive analysis). The graphic depiction of the direct (ui) and the backward (u'i) series derived from this method yields curves, that can overlap one another in the absence of any trend. In the event of a significant trend (the $95 \%$ confidence level), $\mid$ ui $\mid \geq 1.96$, the intersection of the curves makes the time of change roughly possible to discern (Shahid, 2011).

\subsection{Sen's slope estimators}

To evaluate the changes in temperature extreme indices, a common non-parametric test called Sen slope (Sen, 1968) was used. Sen's Slope approach estimated the magnitude of the trend (Sen 1968). A time series dataset is necessary for this procedure. The technique is calculated by computing the path as a unit time change (Shahid, 2011),

$238 \quad Q^{\prime}=\frac{x_{t^{\prime}}-x_{t}}{t^{\prime}-t}$

239 Where,

$240 Q^{\prime}=$ slope between data points $x_{t^{\prime}}$ and $x_{t}$

$x_{t^{\prime}}=$ data measurement at time $t^{\prime}$ 
$x_{t}=$ data measurement at time $t$

243 The median slope simply gives Sen's estimator of the slope,

$Q=Q_{[(N+1) / 2]}^{\prime}$ If $N$ is odd

$$
=\left(Q_{[N / 2]}^{\prime}+Q_{[(N+2) / 2]}^{\prime}\right) / 2 \text { if } N \text { is even }
$$

246 Where,

$247 \mathrm{~N}$ is the number of computed slopes.

\section{$248 \quad 2.5$ Correlation matrix}

249 The Pearson correlation was used to discover the link between temperature and atmospheric oscillation indices. Pearson's correlation measures the direct relationship between two variables, where positive correlation denotes by the value 1 ; if the value of $\mathrm{r}$ is 0 it means no correlation; and negative correlation indicates by the value -1 . $\mathrm{X}$ and $\mathrm{Y}$ are considering two variables, each having $n$ values $X_{1}, X_{2}, \ldots, X n$ and $Y_{1}, Y_{2}, \ldots, Y n$ respectively. Let the mean of $\mathrm{X}$ be $\bar{X}$ and the mean of $\mathrm{Y}$ be $\bar{Y}$. Pearson's $\mathrm{r}$ is calculated following Tomar et al. (2016):

$256 r=\frac{\sum\left(X_{i}-\bar{X}\right)\left(Y_{i}-\bar{Y}\right)}{\sqrt{\sum\left(X_{i}-\bar{X}\right)^{2} \sum\left(Y_{i}-\bar{Y}\right)^{2}}}$

257 The Pearson correlation coefficients have been utilized in the present study to explore the spatial (Northern, Southern and Central) and temporal (1980-1998, 1999-2017 and 19802017) correlation of eight extreme temperature indices with five large-scale oceanic indices. The relationship of the temperature indices with the elevation was explored by performing the least-squares method (Casella and Berger, 2002; Moore and McCabe, 2003).

\section{Results}

\subsection{Trends of the extreme temperature indices}

Table 2 presents the results of the MK trend test of 8 temperature indices in each region and the whole country for 1980-2017. The results showed an increasing trend in TN10p and 
TX10p at $(\mathrm{p}<0.1)$ in all three areas and the entire country (except TN10p). The TNn exhibited an insignificant rising trend in the Central region and whole Bangladesh. The results also showed an increase in TN90p ( $<<0.01$ and whole Bangladesh $p<0.05)$, SU25 $(\mathrm{p}<0.05$ and the Northern region $\mathrm{p}<0.1)$, and TR20 $(\mathrm{p}<0.01)$ during 1980-2017. The TX90p $(\mathrm{p}<0.05)$ and TXx $(\mathrm{p}<0.1)$ were increasing only in the Northern region. The rest of the indices showed an insignificant increasing trend in all regions and the whole country. Figs. 2 and 3 demonstrate the rate of the change of extreme temperature indices found by Sen's slope of the estimator. The blue circles indicate increasing trends, and the red circle represents decreasing trends. TN10p showed an increase in Dhaka at the rate of 2.19 days/decade. The changes in TN10p in Rangpur, Rajshahi, Bogura, Mymensingh, Madaripur, and Cumilla stations were in the range of 0-1 day/decade. The rest of the stations showed a decreasing trend inTN10p at the rate of -1 to -2 days/decade (Figure $2 a$ ). TN90p showed an increase at all stations from 0.62 to 9.91 days/decade, except at Patuakhali $(-1.15$ days/decade) (Figure 2b). TX10p showed a decreasing trend in Bangladesh from -0.04 to 2.31 days/decade (Figure 2c), except at Rangpur (3.34 days/decade), Patuakhali (0.56 day/decade), Sandwip (1.57 days/decade) and Rangamati (1.54 days/decade). The TX90p (Figure 2d) and TR20 (Figure 3d) revealed a similar trend pattern. The TX90p and TR20 were decreasing at Rangamati and Sandwip from -0.13 to -1.25 days/decade. The other stations exhibited an increasing trend inTX90p (0.21 to 4.83 days/decade) and TR20 (1.25 to 10 days/decade). On average, the decreasing trend in TNn was dominant in Bangladesh at a rate of -0.09 to $-0.26{ }^{\circ} \mathrm{C} /$ decade (Figure 3a). All stations in the Southern region showed an increasing trend in TXx from 0.11 to $0.76{ }^{\circ} \mathrm{C} /$ decade (Figure $3 \mathrm{~b}$ ). The SU25 presented a variation from -1.5 to 6.67 days/decade at different locations. Overall, the results showed an increasing trend in warm temperature and a decreasing trend in cold temperature indices, 
indicating hot days and nights are increasing and cold days and nights are decreasing in Bangladesh.

Table 2: The MK test statistics of eight temperature indices during study period

\begin{tabular}{lllll}
\hline \multirow{2}{*}{$\begin{array}{l}\text { Temperature } \\
\text { indices }\end{array}$} & \multicolumn{4}{c}{ Z-value } \\
\cline { 2 - 5 } & Northern & Southern & Central & Bangladesh \\
\hline TN10p & $-2.50 * *$ & $-1.76^{*}$ & $-2.12^{* *}$ & -1.45 \\
TN90p & $2.60 * * *$ & $2.90 * * *$ & $2.75 * * *$ & $2.33 * *$ \\
TX10p & $-3.30 * * *$ & $-2.43 * *$ & $-1.70 *$ & $-2.27 * *$ \\
TX90p & $2.13 * *$ & 0.88 & 0.68 & 0.75 \\
TNn & 0.63 & 0.14 & -0.47 & -0.37 \\
TXx & $1.77 *$ & 0.41 & 1.59 & 1.22 \\
SU25 & $1.90 *$ & $2.38^{* *}$ & $1.98 * *$ & $2.02 * *$ \\
TR20 & $4.17 * * *$ & $3.22 * * *$ & $3.70 * * *$ & $3.58 * * *$ \\
\hline$*$ significant at the 0.01 level; ** significant at the 0.05 level and $*$ significant at 0.1 level
\end{tabular}

\subsection{Temporal variability in extreme temperature indices}

The temporal change in the annual mean temperature extremes in Bangladesh during 19802017 is illustrated in Figure 4. The results showed that the warm indices, TN90p (Fig. 4c), TX90p (Fig. 4d), TR20 (Fig. 4g), and SU25 (Fig. 4h) were increasing significantly with $\mathrm{R}^{2}=0.25(\mathrm{p}<0.01), \mathrm{R}^{2}=0.66(\mathrm{p}<0.01), \mathrm{R}^{2}=0.24(\mathrm{p}<0.01)$ and $\mathrm{R}^{2}=0.05(\mathrm{p}>0.05)$, respectively during 1980-2017. The average decadal values of TN90p, TX90p TR20, and SU25 displayed a considerable increase after the 2000s. However, TXx (Fig. 4e) exhibited non-significance increasing tendency with $\mathrm{R}^{2}=0.01$ ( $\mathrm{p}>0.05$ ). By contrast, the cold indices, TN10p (Fig. 4a), TX10p (Fig. 4b), and TNn (Fig. 4f) showed significant declination with $\mathrm{R}^{2}=0.22$ ( $\mathrm{p}<0.01$ ), $\mathrm{R}^{2}=0.17(\mathrm{p}<0.01)$, and $\mathrm{R}^{2}=0.06(\mathrm{p}<0.05)$, respectively, during the same period.

It indicates an elevation in the frequency of extreme hot indices and declination in extreme cold indices significantly in Bangladesh. It suggests that extreme temperatures in Bangladesh 

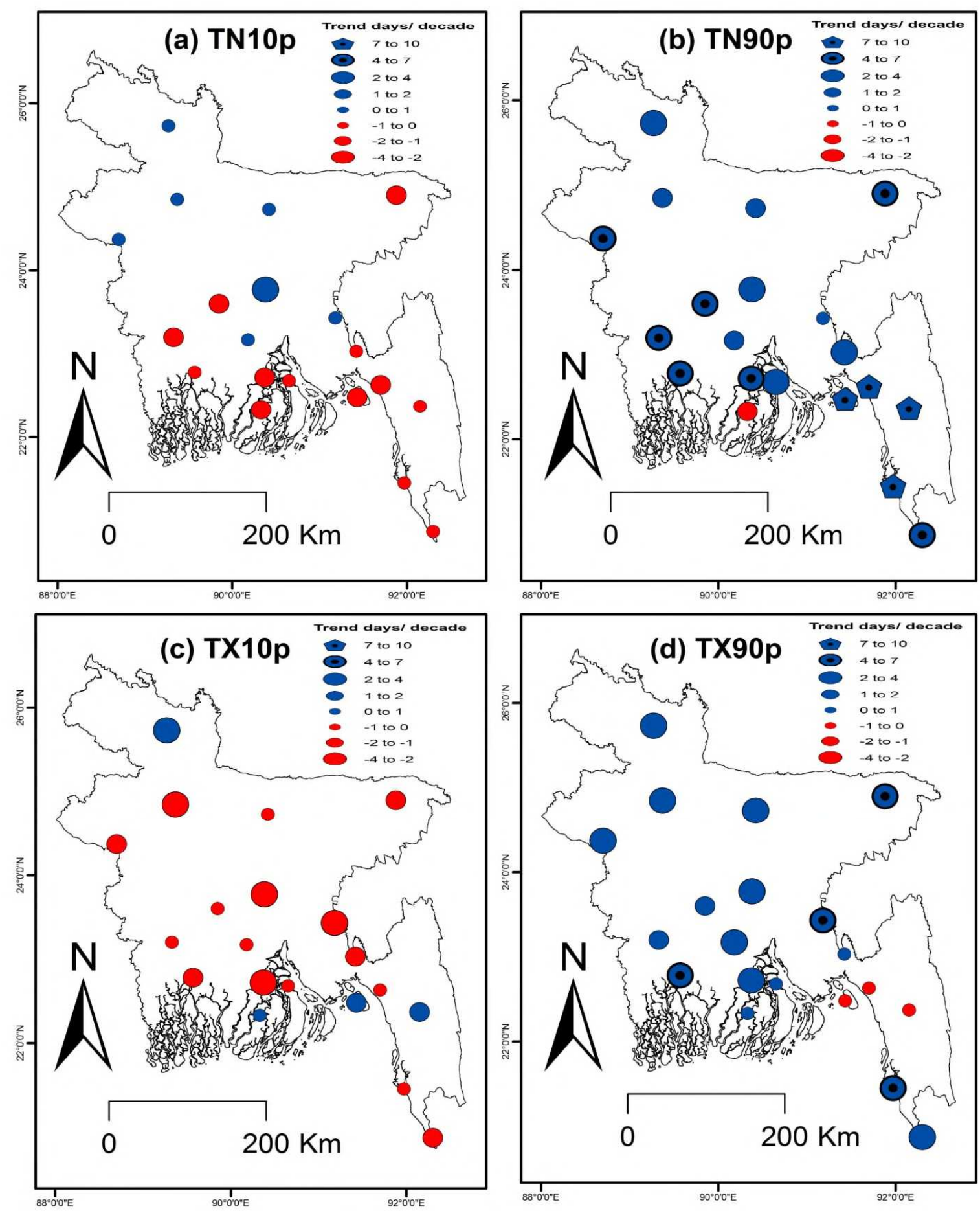

Figure 2: Spatial distribution pttern of trend in TN10p, TN90p, TX10p, and TX90p 

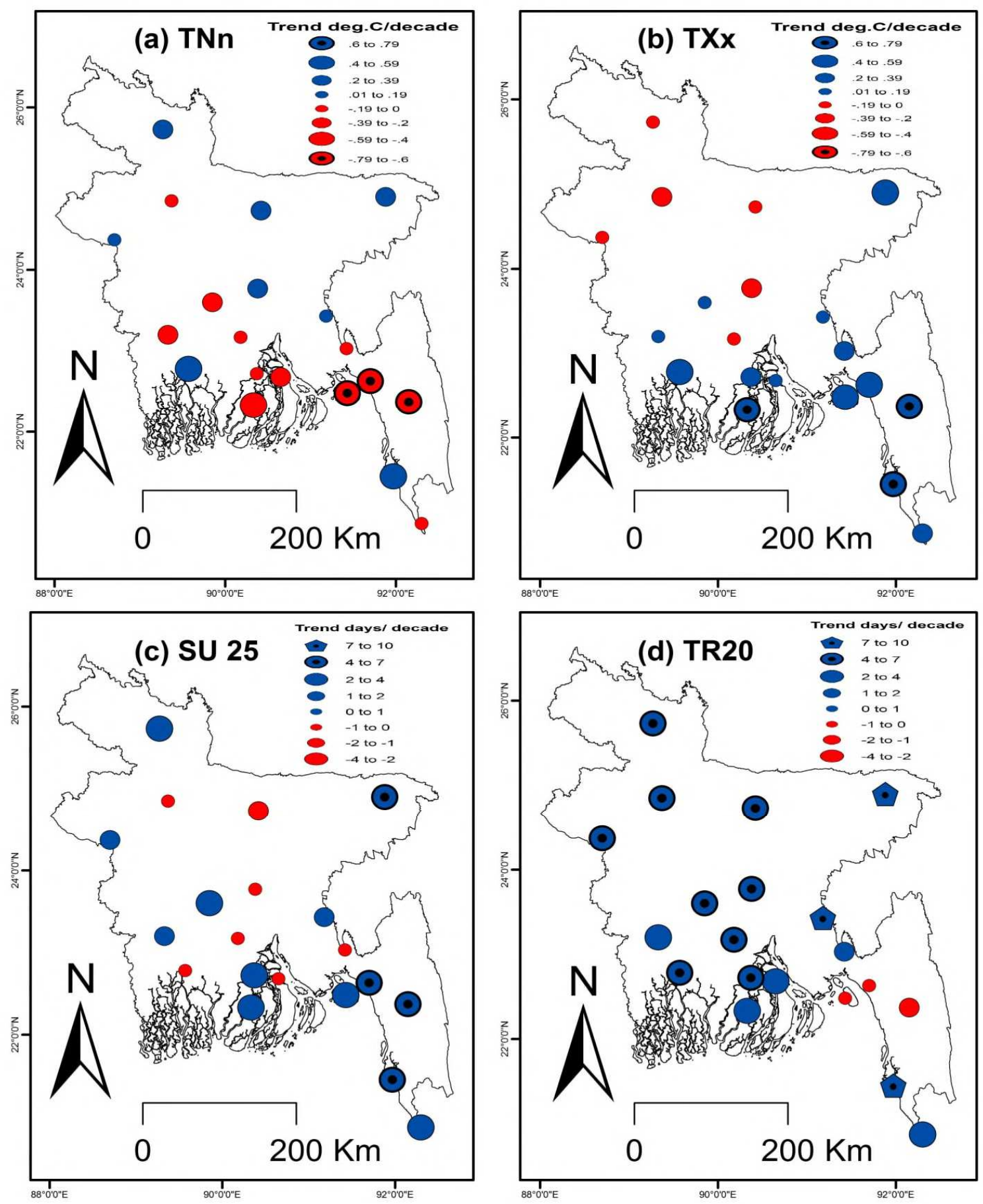


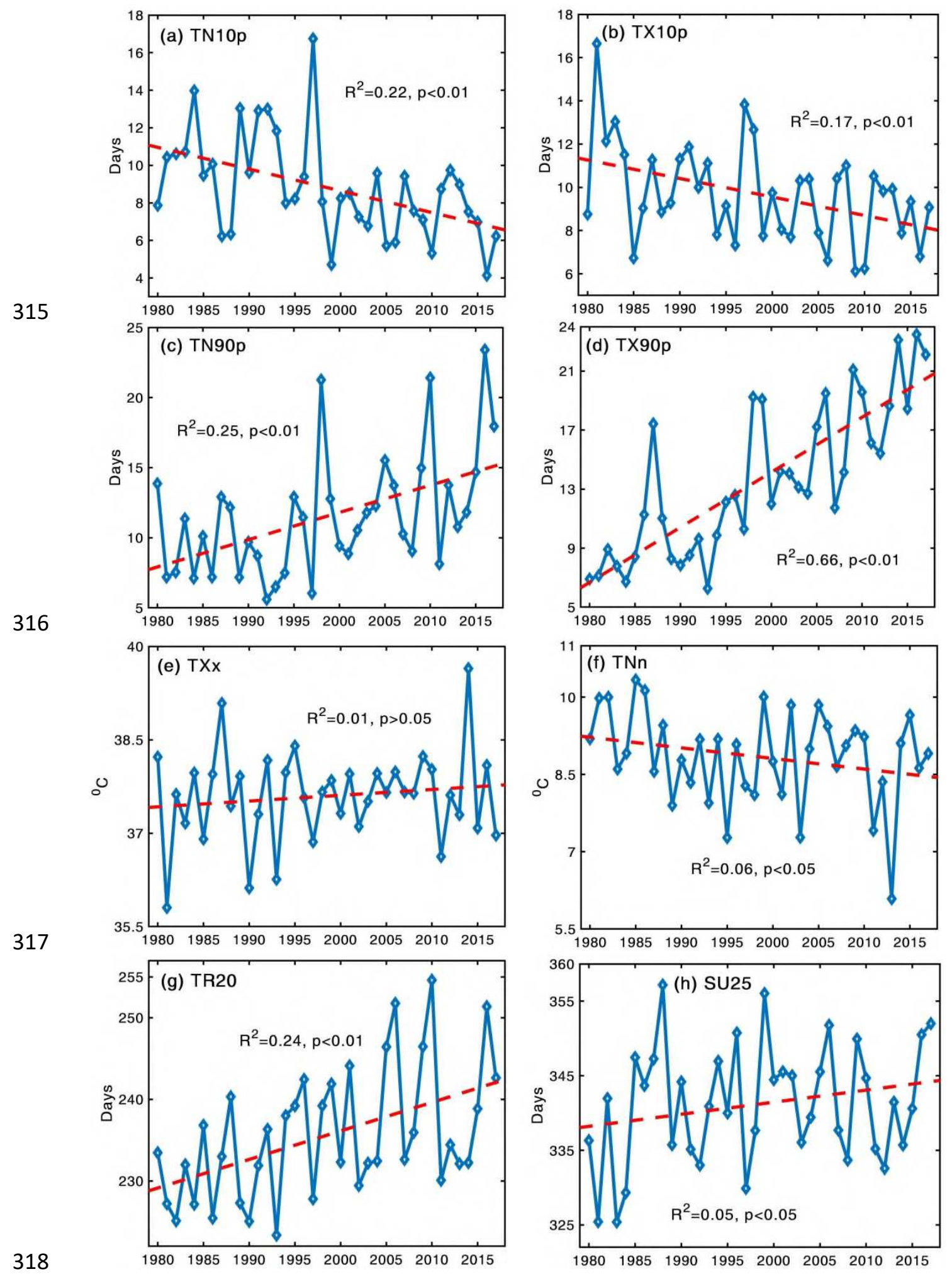

319 Figure 4 The annual mean of temperature extreme indices for this study 
323 The associations of the extreme temperature indices with the ENSO circulation indices in two

324 different periods, 1980-1998 and 1999-2017 and the entire study period, 1980-2017, are

325 shown in Table 3. The results showed a negative correlation of all warm temperature

326 extremes, TX90p (except SST), TN90p (except MEI and SST), TXx (except MEI and SST),

327 SU25, and TR20 with SOI, MEI, IOD, NAO, and SST. The cold temperature extremes,

328 TN10p, TNn (except SOI and NAO) and TX10p showed a positive correlation with SOI,

329 IOD, MEI, NAO and SST during the study period of 1980-2017.

331 Table 3: Pearson correlation coefficient values between temperature indices and climate 332 modes of climatic variability in Bangladesh during 1980-2017

\begin{tabular}{|c|c|c|c|c|c|c|}
\hline \multirow{2}{*}{ Period } & \multirow{2}{*}{ Climate indices } & \multicolumn{5}{|c|}{ Climate modes of climatic variability } \\
\hline & & SOI & MEI & IOD & NAO & SST \\
\hline \multirow{8}{*}{ 1980-1998 } & TNn & .097 & -.301 & .115 & .097 & -.260 \\
\hline & TXx & -.205 & -.005 & -.080 & -.205 & .021 \\
\hline & TN10p & .295 & .324 & .144 & .295 & .329 \\
\hline & TN90p & -.363 & -.115 & -.275 & -.363 & -.207 \\
\hline & TX10p & .318 & $.724^{* *}$ & .311 & .318 & $.636^{* *}$ \\
\hline & TX90p & -.343 & -.080 & -.092 & -.343 & -.068 \\
\hline & SU25 & -.362 & $-.541^{* *}$ & -.064 & -.362 & -.419 \\
\hline & TR20 & $-.517^{* *}$ & -.363 & -.298 & $-.517^{* *}$ & -.386 \\
\hline \multirow{9}{*}{ 1999-2017 } & $\mathrm{TNn}$ & -.177 & .371 & -.107 & -.177 & .373 \\
\hline & TXx & -.305 & .189 & -.369 & -.305 & .150 \\
\hline & TN10p & .108 & -.365 & $.561^{* *}$ & .108 & -.280 \\
\hline & TN90p & -.179 & .419 & $-.522^{* *}$ & -.179 & .335 \\
\hline & TX10p & .300 & -.328 & $.496^{*}$ & .300 & -.304 \\
\hline & TX90p & .169 & .358 & -.448 & .169 & .321 \\
\hline & SU25 & .072 & .258 & -.456 & .072 & .177 \\
\hline & TR20 & -.365 & .171 & -.404 & -.365 & .109 \\
\hline & TNn & -.038 & .031 & .004 & -.038 & .048 \\
\hline
\end{tabular}




\begin{tabular}{rlccccc} 
& TXX & -.267 & .050 & -.189 & -.267 & .068 \\
& TN10p & .282 & .227 & .186 & .282 & .167 \\
& TN90p & -.316 & .020 & -.321 & -.316 & .013 \\
1980-2017 & TX10p & $.354^{*}$ & $.396^{*}$ & .323 & $.354^{*}$ & .287 \\
& TX90p & -.186 & -.070 & -.141 & -.186 & .029 \\
SU25 & -.165 & -.273 & -.195 & -.165 & -.207 \\
& $-.466^{*}$ & -.178 & -.284 & $-.466^{*}$ & -.152 \\
\hline TR20 & ** Correlation is significant at the 0.01 level; *Correlation is significant at the 0.05 level.
\end{tabular}

334

335 Additionally, the TR20 showed a negative correlation with SOI $(\mathrm{p}<0.05)$ and TR20 showed a negative correlation with NAO ( $<<0.05)$. The TXx, TN90p, and TX90p were negatively associated (insignificant) with SOI, IOD, MEI and NAO, and TN10 and TX10p were positively correlated with all the ENSO indices (Table 3). Among the five atmospheric and oceanic circulation patterns, MEI, SST, and IOD showed a comparatively higher positive correlation with temperature indices than SOI and NAO.

341 The correlations of temperature extremes with circulation indices were inconsistent for the two periods (Table 3). None of the extreme temperature indices, except TX10p and TR20, were significantly correlated with circulation indices during 1980-1998. TR20 was negatively correlated with SOI and NAO ( $\mathrm{p}<0.01)$. On the other hand, TX10p was positively correlated with MEI and SST ( $<<0.01)$, and the SU25 also negatively correlated with MEI (p<0.01) during 1980-1998.

347 The warm temperature extremes, TR20, SU25 (except SOI and NAO), TN90p, and TXx were negatively correlated with SOI, IOD, and NAO during 1999-2017 (Table 3). In contrast, the cold temperature extremes (TN10p and TX10p) were positively correlated with SOI, IOD, and NAO. Furthermore, TX90p was positively correlated with all circulation indices except IOD, while TNn was negatively correlated with all the ENSO indices except the MEI and 
SST. Additionally, TN10p was positively associated with IOD $(\mathrm{p}<0.01)$, whereas TX10p was negatively associated with IOD ( $<<0.05)$ during 1999-2017.

354 At different periods within the study time, the association of temperature indices demonstrated various relationships with varying circulation indices at various regions (Table 4). Figures 5 represents the association of temperature indices with IOD circulation indices during 1980-2017. Similarly, the association of temperature indices with IOD circulation indices were also displayed in Supplementary Figs. S1-4 A significant positive relationship of cold extremes with circulation patterns was observed in this study. In contrast, warm extremes and circulation patterns showed a statistically significant negative association in the study area during the study period. The stations showing negative correlation were more than the stations showing positive correlation. TXx, TNn, SU, TR, TN90p, and TX90p were negatively correlated with SOI, MEI and NAO in the north, south, central and whole Bangladesh, and a negative correlation in the northern region. Among them, TN10p, TN90p and TR exhibited a significant negative correlation. In the northern area, all of the warm extremes except TX90p exhibited a negative correlation with SST. However, the correlation was significant only for TR. All the warm and cold extremes except SU showed an insignificant positive association with SST in the southern region. All cold extremes and two warm extremes (TXX and TX90p) positively correlated with SST in the central area. However, the positive correlation was significant only for TN10p. Two temperature extremes, TR and SU showed a negative association with SST for the whole country. In the south, central, and whole Bangladesh, all warm extremes exhibited a negative association with IOD, whereas all cold extremes showed a positive correlation with IOD. In the northern region, all cold and warm extremes except TX10p showed a negative correlation. TN90p exhibited a significant correlation with IOD in all regions. Only TR exhibited a significant negative connection with MEI in the northern area, and all warm 

extremes except TXx showed a negative link with MEI. TX90p, TXx, and SU showed a 378 negative association with MEI. However, the correlation was significant only for SU in the 379 southern region. Four indices, TN10p, TX10p, TX90p, and TXx showed a positive 380 correlation, and the others showed a negative correlation with MEI in the central region. All 381 of the warm extremes except for TN90p demonostrated a negative association, TX10p exhibited a significant positive, and SU showed a significant negative association with MEI for the whole country. 
Table 4 shows that negative correlation was observed more in the different sub-regions with ENSO indices than the positive correlation. In this table extreme temperature indices exhibited more negative association than positive association with the ENSO indices. The significant positive or negative association were mainly limited to the Cold (TN10p and TX10p) and hot (TN90p and TR20) extreme temperature indices with the MEI, NAO and SOI (Table 4). In the northern region, TR20 indices displayed significant negative correlation with the MEI $(\mathrm{r}=-0.411, \mathrm{P}<0.05)$ and NAO $(\mathrm{r}=-0.454, \mathrm{P}<0.01)$ indices and significant positive for $\mathrm{SOI}(\mathrm{r}=-0.411, \mathrm{P}<0.05)$. The cold extreme, TN10p showed also significant positive association with $\mathrm{NAO}(\mathrm{r}=0.447, \mathrm{P}<0.01)$. In the southern region, NAO exhibited significant negative correlation with TR20 $(r=-0.363, \mathrm{P}<0.05)$ and significant positive with cold extreme like TX10p $(\mathrm{r}=0.376, \mathrm{P}<0.05)$. However, in the central region cold extreme (TN10p) indices displayed a significant negative and positive correlation with $\mathrm{SOI}(\mathrm{r}=-0.465$, $\mathrm{P}<0.01)$ and MEI $(\mathrm{r}=0.466, \mathrm{P}<0.01)$, respectively. Moreover, warm extreme indices like TN90p showed a significant negative correlation with NAO $(r=-0.399, P<0.05)$. At last, over the whole TR20 exhibited a significant negative correlation with NAO ( $\mathrm{r}=-0.450, \mathrm{P}<0.01)$. The results exposed that almost all of the positive correlation with ENSO indices was displayed by cold extreme indices (TX10p and TN10p) and most negative correlation was displayed by hot extreme indices (TN90p and TR20) in almost all over the different subregions and the whole country.

Table 4: Pearson correlation coefficient values between extreme temperature indices and climate mode for various periods in different sub-regions and the whole country

\begin{tabular}{lllllll}
\hline \multirow{4}{*}{ North } & & SOI & MEI & IOD & NAO & SST \\
\hline & TN10p & -0.289 & 0.315 & -0.053 & $0.447^{* *}$ & 0.190 \\
& TN90p & 0.286 & -0.241 & -0.094 & -0.275 & -0.095 \\
& TX10p & -0.208 & 0.224 & 0.318 & 0.182 & 0.198 \\
& TN90p & 0.256 & -0.196 & -0.069 & 0.015 & -0.011 \\
& TXx & -0.099 & 0.051 & 0.027 & -0.099 & 0.090 \\
& SU25 & 0.171 & -0.183 & -0.145 & -0.078 & -0.157 \\
& TR20 & $0.368^{*}$ & $-0.411^{*}$ & -0.129 & $-0.454^{* *}$ & -0.252 \\
South & TN10p & -0.096 & 0.080 & 0.140 & 0.096 & 0.009 \\
& TN90p & 0.023 & 0.053 & -0.186 & -0.286 & 0.112 \\
& TX10p & -0.211 & 0.280 & 0.093 & $0.376^{*}$ & 0.132
\end{tabular}




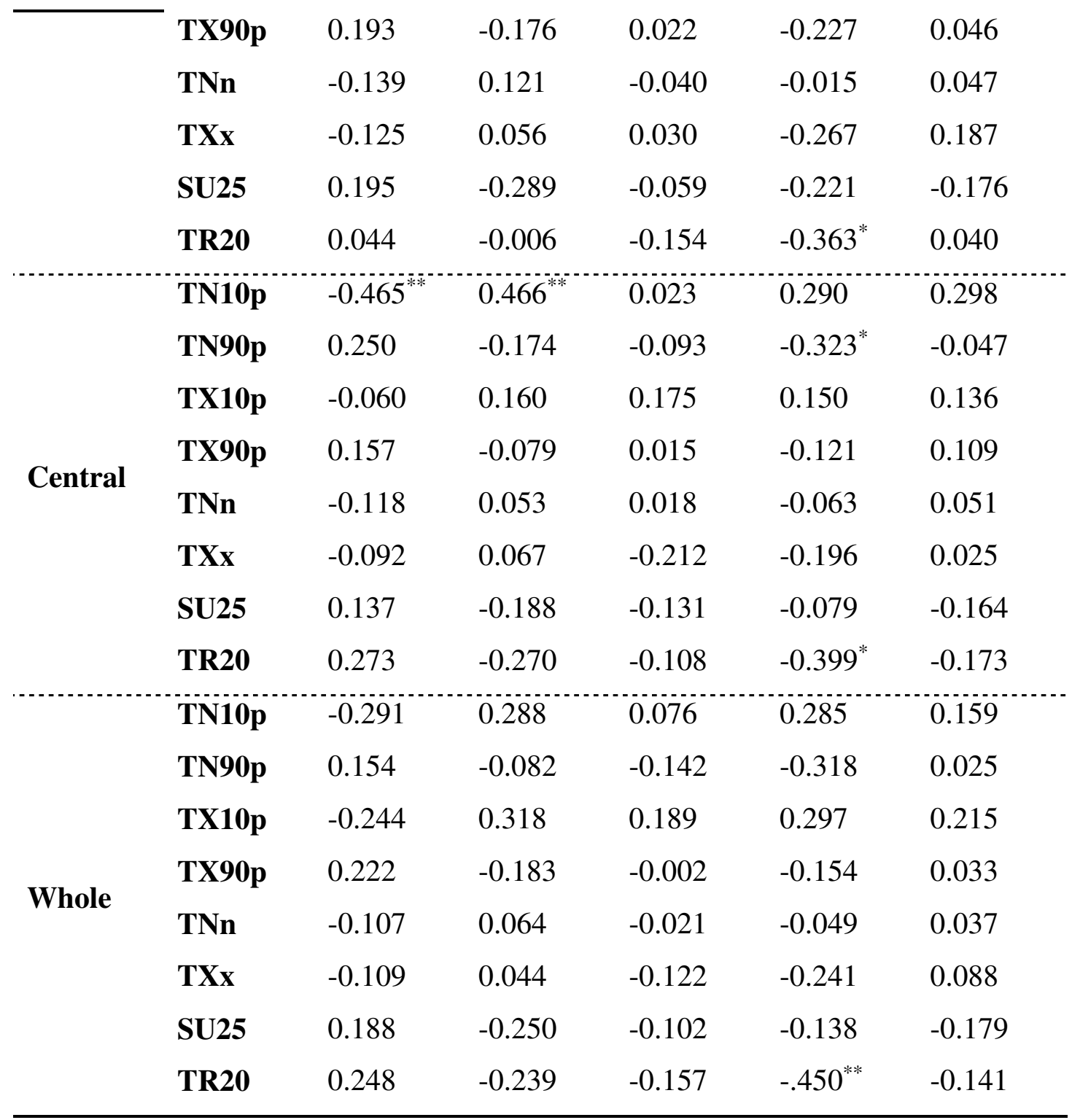

406 $*$ and $* *$ represent significant at the $\mathrm{p}<0.05$ and $\mathrm{p}<0.01$ level, respectively

407 

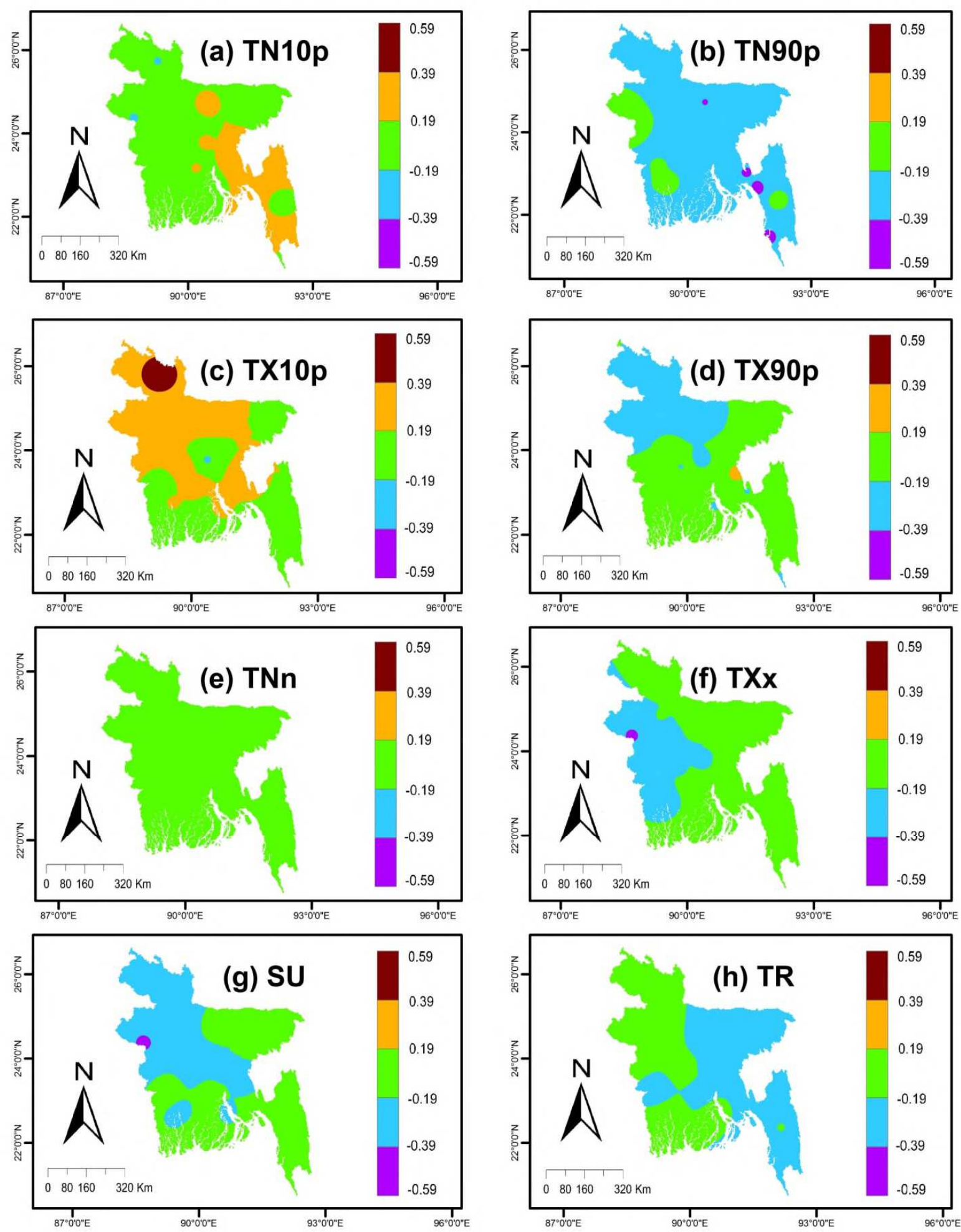

Figure 5: Mapping of the association of extreme temperature indices with IOD

\subsection{Elevation dependency of extreme temperature trends}

411 Figure 6 shows the relationship between the trend magnitude's in temperature extremes and

412 elevation. The results indicated an inconsistent association between the trends in temperature 
extremes and altitude. Except for tropical nights (TR20) and warm nights (TN90p), a

414 significant positive relationship of elevation with warm temperature indices was observed in

415 this study. On the other hand, the cold temperature indices exhibited a significant negative 416 association with elevation except for cold nights (TN10p). The warm days (TX90p), warmest

417 days (TXX), summer days (SU25), and cold nights (TN10p) exhibited a significant positive 418 relationship (Figure 6). The trends of warm nights (TN90p), tropical nights (TR20), coldest 419 days $(\mathrm{TNn})$, showed a substantial decrease with the decrease of elevation $(\mathrm{p}<0.05)$.

420
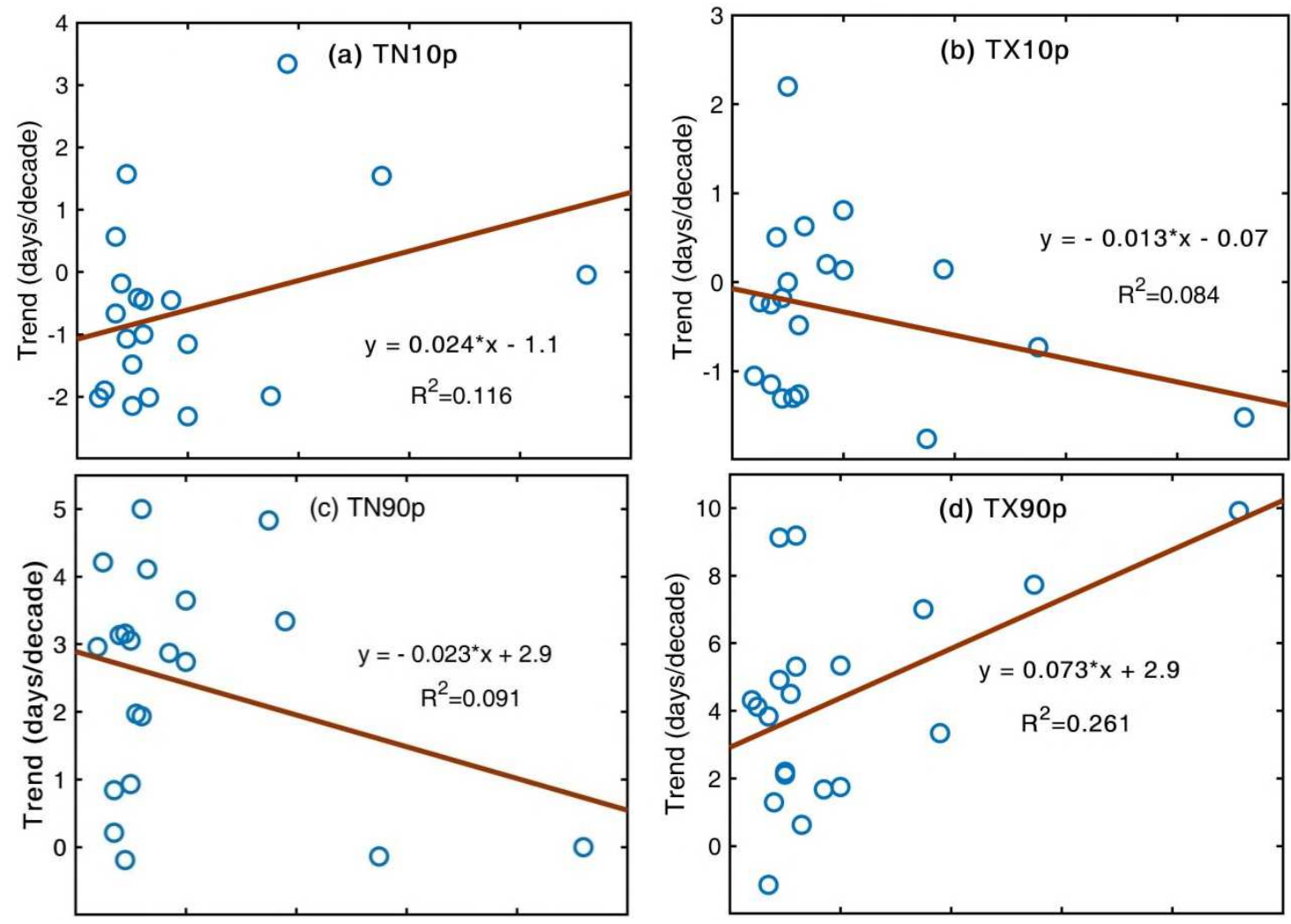

421
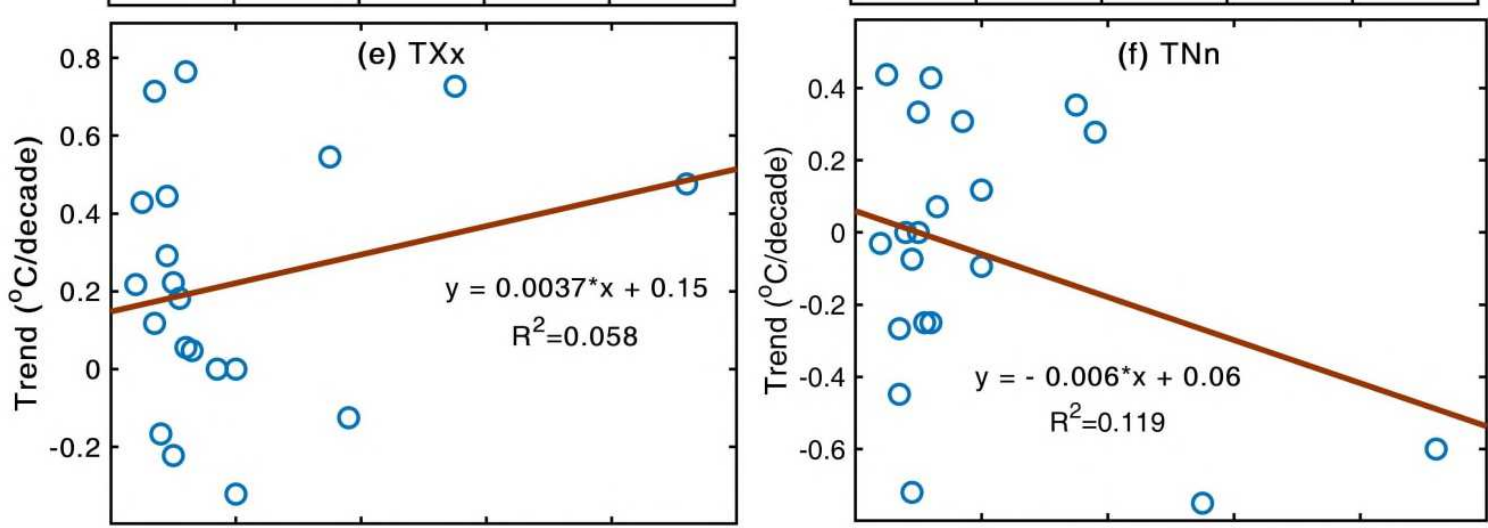

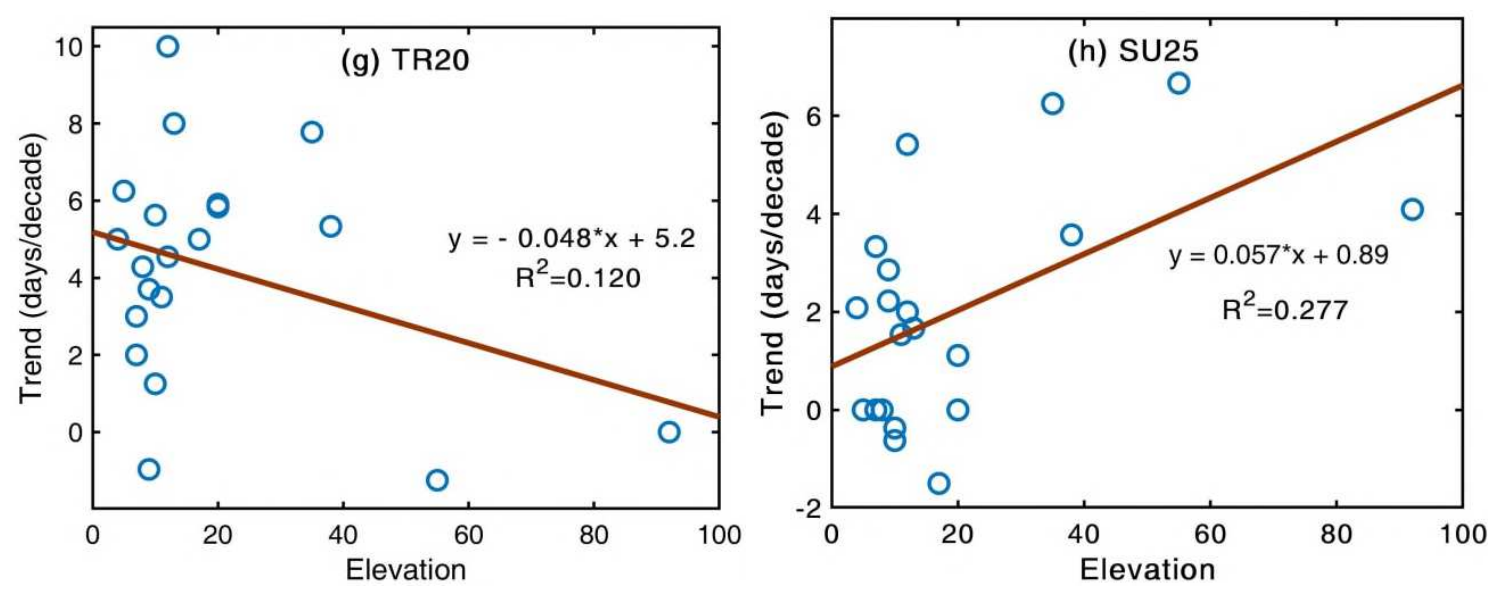

Figure 6 Elevation dependency of the trends in eight temperature extremes during 1980-2017

\subsection{Large-scale atmospheric circulation dependent temperature extreme}

427 The temperature indices had been significantly and abruptly changed found by the sequential MK test. However, the abrupt change point was varied for various temperature indices. After the abrupt change point, the temperature indices trends were either noteworthy upward or downward, and the climatic indices considerably affected the temperature extremes. In general, an abrupt change point of annual average temperatures in Bangladesh for 1980-2017 was in 1995 (Figure 7). Therefore, the change in atmospheric circulation was estimated by subtracting the ERA-interim and ECMWF reanalysis dataset before and after the breaking point, 1980 to 1995 , from 1996 to 2017. The difference in air temperature, wind speed (vectors) and geopotential height (shaded) at $850 \mathrm{hPa}$ between 1980-1995 and 1996-2017 are illustrated in Figure 7. Figure 7a revealed an evident rising in air temperature in the northwestern region, whereas the southern and southeastern areas were subjected to a decline in air temperature.

Similarly, Figure $7 \mathrm{~b}$ represents a decrease in wind speed in the northwest of Bangladesh and an increase in the southeast. Again, the highest geopotential height differences (around 20 gpm) were observed in the northern and northwestern regions. In contrast, the least 

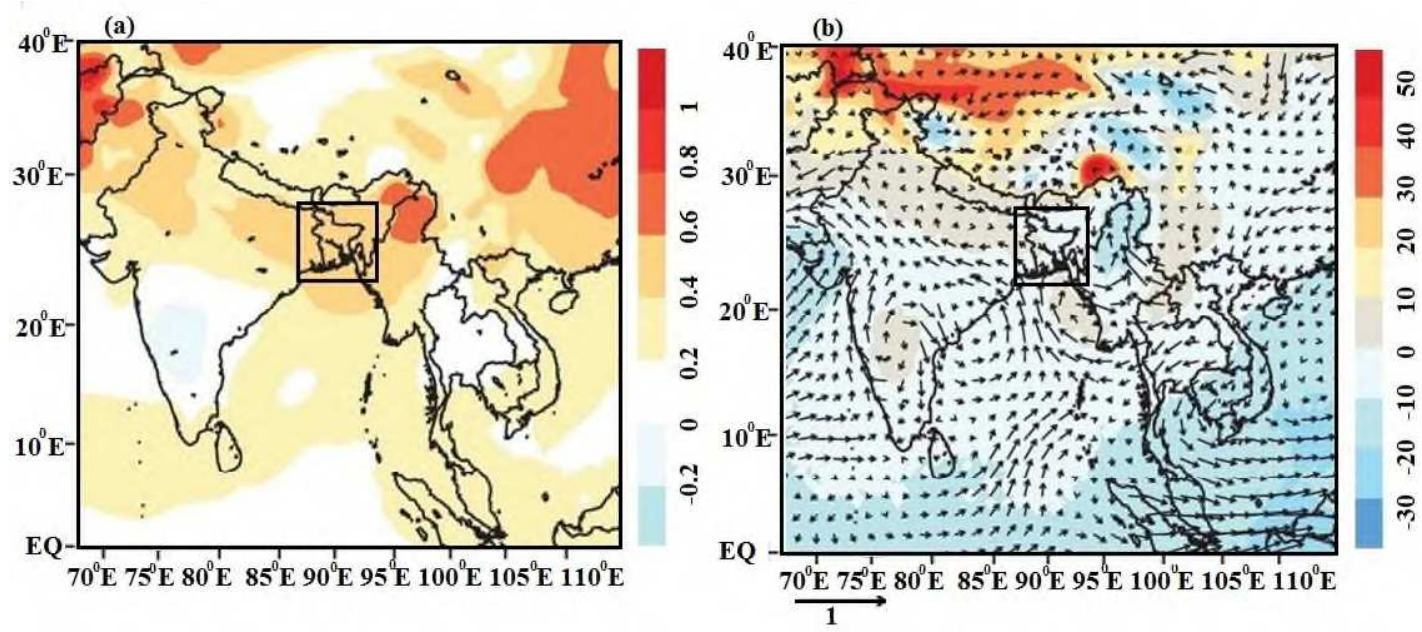

Figure 7 a) Difference of air temperature $\left({ }^{\circ} \mathrm{C}\right)$, b) wind speed and geopotential heights (gpm)

\section{Discussion}

The current study has evaluated the spatial and temporal trends of the eight temperature indices in Bangladesh from 1980 to 2017 . The results revealed that the warm temperature indices(TXx, TX90p, TN90p, TR20, and SU25) were increasing and a decreasing trend (meaning lower temperature was gradually decreasing more than past) in cold temperature indices (TNn, TX10p, and TN10p). The rate of change in different temperature indices was different from each other. Khan et al. (2019) have also shown that the low-temperature trend has been dropping and that maximum temperature trends have been rising in Bangladesh. Abdullah et al. (2020) observed significant warming in Bangladesh's coastal and inland locations, which indicated the increasing trends in high-temperature indices. Khan et al. (2020) found similar results to those found in this study. Daytime warming was shown to be larger than nighttime warming, with high-temperature extremes rising faster than lowtemperature extremes, contradicting the findings of the result of Khan et al. (2019). The datasets and technique utilized in the current analysis differ significantly from those used by 
Khan et al. (2019). The major explanation for the larger rise in hot extremes is owing to a smaller magnitude of warming in summer compared to winter (Abdullah et al., 2020), as well as substantial warming due to greenhouse gas (GHG) radiative effects in summer (Aguilar et al., 2009). The observed warming trend is consistent with findings from studies conducted at both global (Easterling et al., 2000; Alexander et al., 2006) and regional (Sheikh et al., 2015; Klein Tank et al., 2006; Shrestha et al., 2017; Shi et al., 2018; Tong et al., 2019) scales. Temperature indices in the northwest and western areas have been significantly higher recently, but changes in the northeast and southwest have been small. This might be linked to the Sundarban forest's (the world's biggest mangrove forest) ability to store carbon and mitigate the effects of climate change in the southern region of the country (Rahman and Islam et al., 2019). The climate in the northwest and western areas has been heavily impacted by unfavorable land use/land cover changes, urbanization, groundwater depletion, and irrigation modifications (Shahid, 2011).

Atmospheric and ocean oscillations are critical drivers of extreme climate and climate change. Several studies have revealed that the ENSO phenomenon is intimately linked to the interannual monsoon shift in East Asia (Wang and He, 2012; Wahiduzzaman et al., 2020;

477 Ghose et al., 2021a). Large-scale atmospheric oscillation has been a probable reason for the interdecadal fluctuation of cold winter temperature in China (Han et al., 2014). The alteration of the climate mode over the North Atlantic region, regional temperature variations over Northern Eurasia is the results of ENSO, which disturbs the air temperature in winter in Northern China (Wang et al., 2017). The meridional Hadley circulation (MHC) in the western Pacific deteriorated dramatically from the late 1970s. Thus, the response of Asia's atmospheric oscillation to ENSO declining, resulting in a decrease in the responsiveness of 
This study showed a positive correlation of SST with all eight extreme temperature indices in Bangladesh, followed by MEI. In contrast, the extreme temperature indices showed an overall negative correlation with SOI, IOD, and NAO. There was a strong correlation between two temperature indices (TX10p and SU25) and MEI during 1980-1998. The correlation between three temperature indices (TN10p, TN90p, and TX10p) and IOD was significant during 1999-2017. This indicates a greater impact of ENSO on the faster decrease in temperature during cool days and cool nights than the increasing temperature of warm days and nights. Han et al. (2018) reported that the association between the NAO and cool days (nights) in Northeast China varies over time. The variance could be ascribed to NAO-related climate anomalies in different interdecadal backdrops, according to the researchers.

Elevation-dependent temperature extreme (EDTE) has become a hot topic of research for 496 insights into the climate change evidence. A significant number of studies reported that temperature extreme at high altitude is more evident than at low elevation (Sun et al., 2017; Guo et al., 2016; Li et al., 2017; You et al., 2017). By contrast, several studies also revealed no evidence of EDTE (You et al., 2008). The uncertainty in the EDTE may be attributed to diverse meteorological station density, remote areas, and inadequate datasets (Ren et al. 2017; Pellicciotti et al. 2012). Selected temperature indices revealed significant geographic heterogeneity between the higher southeastern and low-lying regions in the current study. Cold night and summer days were the solely minimum and maximum temperature-based indices that showed a significant positive connection with elevation $(\mathrm{P}<0.01)$. The related studies also showed similar findings (Adams et al., 2020; Olmo et al., 2020; Jhajharia et al. 2014; 2021). However, the findings contradict those of Sun et al. (2017) and You et al. (2017), who discovered a definite negative trend in TN10p and FD. The elevation of the eastern region is comparatively higher than other regions of the country. Although, the effects of extreme phenomena on water balance and river flow at the higher elevation remain still 
uncertain due to high climatic variability, remoteness, and the composite action between lithology, climatic and hydrologic processes (Zhou et al., 2020). The present study indicates EDTE in the study region and Bangladesh; however, this evidence is still unclear, and the drivers of the EDTE need systematically examined at regional and national levels.

The large-scale atmospheric and oceanic oscillation variables, such as geopotential height, air temperature, and wind fields influence the local climate. Both spatially and temporally, both the negative and positive effects of large-scale atmospheric oscillation patterns on surface variables and vice-versa. We examined the connection of surface temperature with the changes mentioned above; geopotential height, air temperature, and wind speed are frequently utilized (Tong et al., 2019; Ullah et al., 2018; Jhajharia and Sing, 2011). This study implies that increases in air temperature might also impact the regional as well as local temperature and temperature extremes (Khan et al., 2008; Grotjahn et al., 2016; Ren et al., 2017). Besides, our study reports that the rising geopotential height with reducing in wind speed may be linked to a rising trend in annual mean temperature and their influence on the incidence of extreme temperature phenomena in the northwestern region in some extents (Shahid and Khairulmaini 2009; Xu et al., 2018; Ullah et al., 2018; Shi et al., 2018). The strong wind speeds move towards the southern coastal region from the Bay of Bengal (BoB), which might influence the long-range temperature at a regional scale (Pathak et al., 2017; Sinha et al., 2015). The strong southeast winds transport a considerable amount of water vapours from the BoB to the southern and southwestern coastal regions, which may ultimately influence the regional temperature and resulting in a cold trend and vice versa (Pathak et al., 2017). Long-term forecasting based on ENSO conditions is critical for planning and management in climate-sensitive industries like the environment, and hence deserves more investigation. This study also demonstrated a rising trend of warm extremes in the northwestern regions of Bangladesh, which are in line with the air temperature patterns 
and atmospheric circulation fields. Interestingly, the large-scale atmospheric circulations exhibited a dipole tendency across the northwestern and southeastern regions of the country. Although, exploring the causes and mechanism of this dipole tendency is out of scope in the present study. It deserves further examinations in the future.

The findings of this study might have ramifications for Bangladesh. First, this research showed that Bangladesh may become warmer and drier sooner than previously predicted. The salinity problem in the southwestern area may worsen in the coming days as a result of a considerable increase of severe heat indices. Warming and drying conditions may cause drought in northern and western locations at the same time. To adapt to the drying circumstances, drought-tolerant crop varieties and efficient use of surface water resources may be needed. Second, increased severe temperature events may have an impact on vegetation dynamics, leading to an increase in pests and disease. As a result, this area merits further attention and in-depth research.

There are some shortcomings in this work that must be addressed. First, the transition sites between climatic extremes were not extensively examined, which might be due to a lack of metadata support. The addition of information to the homogenization process may result in improved results. Second, GHG emissions and anthropogenic aerosols were not taken into account, potentially increasing the probability of climate extremes. Despite these constraints, our research examines the spatiotemporal variations in temperature extremes and their links to climate mode in great detail. The findings of this research can aid policymakers in formulating strategies for developing an early warning system and reducing the effects of growing temperature extremes in Bangladesh.

\section{Conclusion}

The current study looked at the spatial and temporal changes in recent temperature extremes in Bangladesh and their teleconnection to atmospheric oscillation indices durig the study 
period (1980-2017). All temperature indices exhibited a difference in the line of the global warming trend. The study revealed decreases in cool nights, coldest days, cold days, and the rises of tropical nights, warmest days, warm nights, warm days, and summer days in nearly all sub-regions of Bangladesh. The magnitudes of the change in warm days/nights were higher than those on cold nights/days. Cold temperature indices were highly associated with large-scale climate indices, while warm temperature indices were weakly associated with atmospheric oscilation indices during the observation period. Variations in recent extreme temperatures were also coupled with some climatic patterns. The areal mean warm extremes of Bangladesh were linked to SST and MEI, and the cold extremes were related to SOI, IOD, and NAO. The association between temperature extreme indices and climate oscillation modes was diverse at various periods. Atmospheric oscillation indices influenced the decreasing temperature of cold days/nights more than the warm days/nights. The alternation of several temperature extremes was linked to the SST and MEI indices in some regions of Bangladesh Besides, they were also associated with SOI and MEI in some sub-regions. The variations of the cold nights and tropical nights were related to NAO and SOI in the north, south, and central regions of Bangladesh, while the cold days were associated with IOD for the whole country.. The cold nights and summer days significantly connected with elevation, suggesting increased cold nights and summer days with increasing elevation in Bangladesh. The changes in large-scale climate mode originated from ERA reanalysis data demonostrated a a strong (weak) wind speed, enhancing (decreasing) geopotential height, and fast warming 580 (cooling) over the northwestern (southeast) region which may attribute to the variations in temperature extremes in Bangladesh.

582 The findings may contribute to assess climate change-related disaster management and infrastructural development planning of the country both for policy and implementation

584 levels. The outcomes of the research will aid in climate change adaptation and climatological 
disaster mitigaiton. This study will also assist policymakers in developing policies to adapt to climate change. The findings would contribute to enriching knowledge on temperature fluctuations with large-scale atmohspheric oscillation indices and elevations over Bangladesh. This study suggests that the natural and human-induced factors of temperature extremes and their probable connections with climate mode should deserve further studies.

\section{Acknowledgment}

The authors would like to thanks the Bangladesh Meteorological Department (BMD) for providing datasets for this research.

\section{Ethical approval}

Not applicable

\section{Consent to Participate}

Not applicable

\section{Consent to Publish}

Not applicable

\section{Data availability}

Data are available upon request on the corresponding author

\section{Author contributions}

A.R.M.T.I., J.M., and H.M.T.I., designed, planned, conceptualized, drafted the original manuscript, and H.M.T.I., were involved in statistical analysis, interpretation; R..S., S.C.P., T.R.R., and M.K., contributed instrumental setup, data analysis, validation; S.S., S.A.B., and A. E., contributed to editing the manuscript, literature review, proofreading; M. K., A.R.M.T.I., S.S., H.M. T.I., and S.M.I., were involved in software, mapping, and proofreading during the manuscript drafting stage.

\section{Conflict of interest}

This material can be published without fear of a conflict of interest. 
612 The authors thank the Deanship of Scientific Research at King Khalid University for supporting this research through Research Group (R.G.P.2 /194/42). This research was also funded by King Saud University's Researchers Supporting Project number (RSP-2021/100).

615

616

617

618

619

620

621

622

623

624

625

626

627

628

\section{References}

1. Abdullah, A. Y. M., Bhuian, M. H., Kiselev, G., Dewan, A., Hasan, Q. K., \& Rafiuddin, M. (2020). Extreme temperature and rainfall events in Bangladesh: a comparison between coastal and inland areas. International Journal of Climatology.

2. Adams, R.E., Lee, C.C., Smith, E.T., Sheridan, S.C., 2020. The relationship between atmospheric circulation patterns and extreme temperature events in North America, International Journal of Climatology, https://doi.org/10.1002/joc.6610

3. Aguilar, E., Barry, A.A., Brunet, M., Ekang, L., Fernandes, A., Massoukina, M., Mbah, J., Mhanda, A., Nascimento, D.J.D., Petersion, T.C., Umba, O.T., Tomou, M., Zhang, X., 2009. Changes in temperature and precipitation extremes in western central Africa, Guinea Conakry, and Zimbabwe, 1955-2006. J. Geophys. Res. Atmos. 114 (D2), 356-360.

4. Alexander, L.V., Zhang, X., et al., 2006. Global observed changes in daily climate extreme of temperature and precipitation. J. Geophys. Res., 111, D05109. http:// dk.doi.org/10.1029/2005JD006290.

5. Almazroui M, Islam MN, Dambul R, Jones PD (2014) Trends of temperature extremes in Saudi Arabia. Int J Climatol 34:808-826. doi:10.1002/joc.3722

6. Casella G, Berger RL. 2002. Statistical inference (2nd ed.), 660.

7. Das, S (2021). Extreme rainfall estimation at ungauged locations: Information that needs to be included in low-lying monsoon climate regions like Bangladesh. J. Hydrol. 601, 126616.

8. Das S, Islam ARMT (2021) Assessment of mapping of annual average rainfall in a tropical country like Bangladesh: remotely sensed output vs. kriging estimate, Theoretical and Applied climatology, DOI: 10.1007/s00704-021-03729-3

9. Dey NC, Parvez M, Islam MR (2021) A study on the impact of the 2017 early monsoon flash flood: Potential measures to safeguard livelihoods from extreme climate events in the haor area of Bangladesh, International Journal of Disaster Risk Reduction, 59, 102247. 
10. Durre I, Wallace JM, Lettenmaier DP (2000) Dependence of extreme daily maximum temperature on antecedent soil moisture in the contiguous United States during summer. J Clim 13:2

11. Easterling, D.R., Meehl, G.A., Parmesan, C., Changnon, S.A., Karl, T.R. and Mearns, L.O., 2000. Climate extremes: observations, modeling, and impacts. Science, 289: $2068-2074$.

12. Eckstein, D., Künzel, V. \& Schäfer, L. 2017. Global climate risk index 2018. Germanwatch, Bonn.

13. Gao, Y., Feng, Q., Liu, W., Lu, A., Wang, Y., Yang, J., Cheng, A., Wang, Y., Su, Y., Liu, L., Ma, Q., 2015. Changes of daily climate extremes in Loess Plateau during 1960-2013. Quat. Int. 371 (1), 5-21

14. Ghose B, Islam ARMT, Islam HMT, Hasanuzzaman M, Huang J, Hu Z, Moniruzzaman M, Gustave W, Karim M, Ibrahim SI (2021) Rain-Fed Rice Yield Fluctuation to Climatic Anomalies in Bangladesh, International Journal of Plant Production, doi: 10.1007/s42106-021-00131-X

15. Ghose B, Islam ARMT, Kamruzzaman M, Moniruzzaman M, Hu Z (2021) Climateinduced rice yield anomalies linked to large-scale atmospheric circulation in Bangladesh using multi-statistical modeling, Theoretical and Applied climatology, DOI: $10.1007 / \mathrm{s} 00704-021-03584-2$

16. Grotjahn, R., Black, R., Leung, R., Wehner, M.F., et al. 2016. North American extreme temperature events and related large-scale meteorological patterns: a review of statistical methods, dynamics, modeling, and trends. Climate Dynamics 46(3-4): 1151-1184.

17. Guo, X., Wang, L., and Tian, L., 2016. Spatio-temporal variability of vertical gradients of major meteorological observations around the Tibetan Plateau. International Journal of Climatology 36(4): 1901-1916.

18. Han, F., Chen, H. and Ma, H., 2018. Interdecadal variat ion in the relationship between North Atlantic Oscillation and extreme low temperature over northern China in winter. Chin. J. Atmos. Sci. 42(2), 239-250.

19. Han. W., Wei. J. and Shen. X., 2014. Stability analysis in space-time on the response of winter temperature in China to ENSO in the past 50 years. Climatic and Environmental Research 19(1), 97-106.

20. Hans, A., 1986. A homogeneity test applied to precipitation data. Int. J. Climatol. 6 (6), 661-675. 
21. Hansen, J.I., Fung, A., Lacis, D., Rind, S., Lebedelt, R., Ruedy, G. and Stone, P. 1988. Global climate changes as forecast by Goddard Institute for Space Studies three dimensional model. J. Geophys. Res., 93: 9341-9364.

22. IPCC (2014) Climate change 2014: synthesis report. Contribution of Working Groups I, II and III to the Fifth Assessment Report of the Intergovernmental Panel on Climate Change. In: Core Writing Team, Pachauri RK and Meyer LA. (eds). IPCC, Geneva, $151 \mathrm{pp}$

23. Islam ARMT, Islam HMT, Shahid S, Khatun MK, Ali MM, Rahman MS, Ibrahim SM, Almoajel AM (2021a). Spatiotemporal nexus between vegetation change and extreme climatic indices and their possible causes of change. Journal of Environmental Management, 289, 112505.

24. Islam HMT, Islam ARMT, et al. (2021b). Spatiotemporal changes and modulations of extreme climatic indices in monsoon-dominated climate region linkage with largescale atmospheric oscillation. Atmospheric Research, 105840. https://doi.org/10.1016/j.atmosres.2021.105840.

25. Islam, A.R.M.T., Ahmed. I., Rahman, M.S., 2020b. Trends in cooling and heating degree-days overtimes in Bangladesh? An investigation of the possible causes of changes, Natural Hazards, 101:879-909 doi: 10.1007/s11069-020-03900-5

26. Islam, A.R.M.T., Rahman, M.S., Khatun, R., Hu, Z., 2020a. Spatiotemporal trends in the frequency of daily rainfall in Bangladesh during 1975-2017, Theoretical and Applied climatology, 141(3-4), 869-887. DOI: 10.1007/s00704-020-03244-X

27. Kamruzzaman, M., Hwang, S., Cho, J., Jang, M-W., Jeong, H.2019b. Evaluating the Spatiotemporal Characteristics of Agricultural Drought in Bangladesh Using Effective Drought Index. Water11(12):2437. https://doi.org/10.3390/w11122437

28. Islam ARMT, Shen S, Yang SB, Hu Z, Chu R (2019). Assessing recent impacts of climate change on design water requirement of Boro rice season in Bangladesh. Theor. Appl. Climatol. 138, 97-113.

29. Jerin JN., Islam HMT, Islam ARMT et al. (2021). Spatiotemporal trends in reference evapotranspiration and its driving factors in Bangladesh. Theor Appl Climatol 144, 793-808. https://doi.org/10.1007/s00704-021-03566-4

30. Jhajharia D, Dinpashoh Y, Kahya E, Choudhary RR, Singh VP (2014) Trends in temperature over Godavari river watershed in southern peninsular India. Inter J Climatology 34: 1369-1384. 
31. Jhajharia D, Singh VP (2011) Trends in temperature, diurnal temperature range and sunshine duration in Northeast India. International Journal of Climatology, 31(9), 1353-1367.

32. Jhajharia et al. (2021) Pan evaporative changes in transboundary Godavari River basin, India. Theoretical and Applied Climatology, 145, 1503-1520.

33. Kamruzzaman, M., Jang, M-W., Cho, J., Hwang, S. 2019a. Future Changes in Precipitation and Drought Characteristics over Bangladesh under CMIP5 Climatological Projections. Water 11(11):2219. https://doi.org/10.3390/w11112219

34. Katz, R.W. and Brown, B.G., 1992. Extreme events in a changing climate: variability is more important than averages. Clim. Change, 21: 289-302.

35. Kendall, M.G., 1975. Rank Correlation Measures. 1. Charles Griffin, London, pp. 2555.

36. Khan, M. H. R., Rahman, A., Luo, C., Kumar, S., Islam, G. A., \& Hossain, M. A. (2019). Detection of changes and trends in climatic variables in Bangladesh during 1988-2017. Heliyon, 5(3), e01268.

37. Khan MJU, Islam AKMS, Bala SK, Islam GMT (2020) Changes in climate extremes over Bangladesh at $1.5{ }^{\circ} \mathrm{C}, 2{ }^{\circ} \mathrm{C}$, and $4{ }^{\circ} \mathrm{C}$ of global warming with high- resolution regional climate modeling. Theor. Appl. Climatol. 140, 1451-1466. https://doi.org/10.1007/s00704-020-03164-w.

38. Khan, T.M.A., Khan, F. A. and Jilani, R., 2008. Sea surface temperature variability along Pakistan coast and its relation to El NiNo- southern oscillation. Journal of Basic and Applied Sciences 4(2): 67-72.

39. Klein Tank, A.M.G., Peterson, T.C, et al. (2006). Changes in daily temperature and precipitation extremes in central and south Asia.J. Geophys. Res., 111, D16105, doi:10.1029/ 2005JD006316.

40. Li M, Chu R, Shen S, Islam ARMT (2018) Dynamic analysis of pan evaporation variations in the Huai River Basin, a climate transition zone in eastern China, Science of The Total Environment, Elsevier, SCOPUS/ISI Index, IF: 6.55, 625:496-509, doi: 10.1016/j.scitotenv.2017.12.317.

41. Li, J., Chen, Y.D., Gan, T.Y. and Lau, N.C., 2018. Elevated increases in humanperceived temperature under climate warming. Nature Climate Change 8(1): 43-47.

42. Li, X., Wang, L., Guo, X. and Chen, D., 2017. Does summer precipitation trend over and around the Tibetan Plateau depend on elevation? International Journal of Climatology 37(1): 1278-1284. 
43. Mann, H. B. 1945. Nonparametric tests against trend. Econometrica, 13:245-259, doi: 00129682(194507)13:3<245:NTAT>2.0.CO;2-U.

44. Mearns, L.O., Katz, R.W. and Schneider, S.H., 1984. Extreme hightemperature events: changes in their probabilities with changes in mean temperature. J. Clim., 23: 1601-1613.

45. Mia, N.M., 2003. Variation of temperature in Bangladesh. Proccedings of SAARC seminar on climatic variability in the South Asian region and its impacts, SAARC Meterological Research Center, pp. 94-97.

46. Moberg, A. and Jones, P.D., 2005. Trends in indices for extremes in daily temperature and precipitation in Central and Western Europe 1901-1999.Int. J. Climatol., 25: 1173-1188.

47. Moore, D. and McCabe, G., 2003. Introduction to the Practice of Statistics. W. H. Freeman and Co., London, UK.

48. Nishat, A. and Mukherjee, N. 2013. Climate change impacts, scenario and vulnerability of Bangladesh, In R. Shaw et al. (eds), Climate Change Adaptation Actions in Bangladesh, DOI 10.1007/978-4-431-54249-0_2.

49. Nowreen S et al (2012) An indicator of climate change in the south west region of Bangladesh. Int J Clim Chang Impacts Response 4(3): 47-60

50. Olmo, M., Bettolli, M.L., Rusticucci, M., 2020. Atmospheric circulation influence on temperature and precipitation individual and compound daily extreme events: Spatial variability and trends over southern South America, Weather and Climate Extremes, 29, 100267.

51. Pathak, A., Ghosh, S., Kumar, P. and Murtugudde, R., 2017. Role of Oceanic and Terrestrial Atmospheric Moisture Sources in Intraseasonal Variability of Indian Summer Monsoon Rainfall. Scientific Reports 7(1): 1-11.

52. Pellicciotti, F., Buergi, C., Immerzeel, W.W., Konz, M. and Shrestha, A.B., 2012. Challenges and Uncertainties in Hydrological Modeling of Remote Hindu KushKarakoram-Himalayan (HKH) Basins: Suggestions for Calibration Strategies. Mountain Research and Development 32(1): 39-50.

53. Piao S, Ciais P, Huang Y, Shen Z, Peng S, Li J, Zhou L, Liu H, Ma Y, Ding Y (2010) The impacts of climate change on water resources and agriculture in China. Nature $467: 43-51$

54. Praveen, B., Talukdar, S., Shahfahad, Mahato, S., Mondal, J., Sharma, P., Islam, A.R.M.T., Rahman, A., 2020. Analyzing trend and forecasting of rainfall changes in 
India using non-parametrical and machine learning approaches. Scientific Reports, 10(1). doi:10.1038/s41598-020-67228-7.

55. Rahman, M. S., \& Islam, A. R. M. T., 2019. Are precipitation concentration and intensity changing in Bangladesh overtimes? Analysis of the possible causes of changes in precipitation systems. Science of The Total Environment, 690:370387. doi:10.1016/j.scitotenv.2019.06.529

56. Ren, Y.Y., Ren, G.Y., Sun, X.B., Shrestha, A.B., You, Q.L., Zhan, Y.J., Rajbhandari, R., Zhang, P.F. and Wen, K.M., 2017. Observed changes in surface air temperature and precipitation in the Hindu Kush Himalayan region over the last 100-plus years. Advances in Climate Change Research 8(3): 148-156.

57. Sacks, W.J. and Kucharik, C.J., 2011. Crop management and Phenology trends in the U.S. corn belt: Impacts on yields. Agric. For. Meteorol., 151: 882-894.

58. Salam R, Islam ARMT (2020) Potential of RT, Bagging and RS ensemble learning algorithms for reference evapotranspiration prediction using climatic data-limited humid region in Bangladesh, Journal of Hydrology, Elsevier, SCOPUS/ISI Index, IF: 4.50, 590, 125241. https://doi.org/10.1016/j.jhydrol.2020.125241

59. Sarker, M.A.R., Alam, K. and Gow, J., 2012. Exploring the relationship between climate change and rice yield in Bangladesh: An analysis of time series data. Agric. Syst.,112: 11-16.

60. Sen, P.K., 1968. Estimates of the regression coefficient based on Kendall's tau. J Am Stat Assoc 63:1379-1389.

61. Shahid S (2009) Spatio-temporal variability of rainfall over Bangladesh during the time period 1969-2003. Asia Pac J Atmos Sci 45:375-389

62. Shahid, S., 2011, Trends in extreme rainfall events of Bangladesh, Theor Appl Climatol. 104:489-499, doi: 10.1007/s00704-010-0363-y.

63. Shahid, S., Khairulmaini, O.S., 2009. Spatio-temporal variability of rainfall over Bangladesh during the time period 1969-2003. APJAS 45 (3), 375-389.

64. Shahid, S., Wang, X., Harun, S.B., Shamsudin, S.B., Ismail, T. and Minhans, A., 2016. Climate variability and changes in the major cities of Bangladesh: observations, possible impacts and adaptation. Reg. Environ. Change, 16:459-471

65. Sheikh, M., Manzoor, N., Ashraf, J., Adnan, M., Collins, D., Hameed, S., Manton, M.,Ahmed, A., Baidya, S. \& Borgaonkar, H., 2015. Trends in extreme daily rainfall and temperature indices over South Asia. Int J Climatol. 35, 1625-1637. 
66. Shi, J., Cui, L., Ma, Y., Du, H. and Wen, K., 2018. Trends in temperature extremes and their association with circulation patterns in China during 1961-2015. Atmos, doi:10.1016/j.atmosres.2018.05.024.

67. Shrestha, A. B., Bajracharya, S. R., Sharma, A. R., Duo, C. \& Kulkarni, A. 2017. Observed trends and changes in daily temperature and precipitation extremes over the Koshi river basin 1975-2010. Int J Climatol. 37, 1066-1083.

68. Sikder, R. and Xiaoying, J., 2014. Climate change impact and agriculture of Bangladesh. J. Environ. Earth Sci., 4 (1):35- 40. www.iiste.org.

69. Sinha, A., Kathayat, G., Cheng, H., Breitenbach, SF., Berkelhammer, M., Mudelsee, M., Biswas, J., Edwards, R.L., 2015 Trends and oscillations in the Indian summer monsoon rainfall over the last two millennia. Nat Commun., 6, 6309.

70. SMRC (2009) Understanding the rainfall climatology and detection of extreme weather events in the SAARC region: Part II- Utilization of RCM data. SAARC Meteorological Research Centre (SMRC), Dhaka

71. Sun Y, Zhang X, Zwiers FW, Song L, Wan H, Hu T, Yin H, Ren G (2014) Rapid increase in the risk of extreme summer heat in Eastern China. Nat Clim Chang 4:1082-1085. doi:10.1038/NCLIMATE2410

72. Sun, X.B., Ren, G.Y., Shrestha, A.B., Ren, Y.Y, You, Q.L., Zhan, Y.J., Xu, Y. and Rajbhandari, R., 2017. Changes in extreme temperature events over the Hindu Kush Himalaya during 1961-2015. Advances in Climate Change Research 8(3): 157-165.

73. Tomar, A. S., Srivastava, A. and Kumar, S., 2016. An implementation of pearson correlation method for predicting items to user in e-commerce. International journal of engineering sciences \& research technology, 5 (7).

74. Tong, S., Li, X., Zhang, J., Bao, Y., Bao, Y., Na, L., Si, A., 2019. Spatial and temporal variability in extreme temperature and precipitation events in Inner Mongolia (China) during 1960-2017. Sci. Total Environ. 649, 75-89.

75. Ullah, S., You, Q., Ullah, W., Ali, A., Xie, W. and Xie, X., 2018. Observed Changes in Temperature Extremes over China-Pakistan Economic Corridor during 1980-2016, Atmospheric Research, doi: 10.1002/joc.5894.

76. Viola F, Liuzzo L, Noto LV, Conti FL, Loggia GL (2014) Spatial distribution of temperature trends in Sicily. Int J Climatol 34:1-17. doi:10.1002/joc.365 
77. Wahiduzaman M, Islam ARMT, Luo J, Shahid S, Uddin MJ, Shimul SM, Sattar MA (2020) Trends and variabilities of thunderstorm days over Bangladesh on the ENSO and IOD timescales, Atmosphere, 11(11), 1176, doi: 10.3390/atmos11111176

78. Wahiduzzaman M, Luo J (2020) A statistical analysis on the contribution of El NiñoSouthern Oscillation to the rainfall and temperature over Bangladesh. Meteorol Atmos Phys 1-14:55-68. https://doi.org/10. 1007/s00703-020-00733-6

79. Wang, G., Yan, D., He, X., Liu, S., Zhang, C., Xing, Z., Kan G., Qin, T., Ren, M. and Li, H., 2017, Trends in extreme temperature indices in Huang-Huai-Hai River Basin of China during 1961-2014, Theor Appl Climatol, doi 10.1007/s00704-017-2252-0.

80. Wang, H. and He, S., 2012. Weakening relat ionship between East Asian winter monsoon and ENSO after mid-1970s. Chin. Sci. Bull. 57(27), 3535-3540.

81. Xu, M., Kang, S., Wu, H. and Yuan, X., 2018. Detection of spatio-temporal variability of air temperature and precipitation based on long-term meteorological station observations over Tianshan Mountains, Central Asia. Atmospheric Research 203(12): 141-163.

82. You, Q., Kang, S., Pepin, N., and Yan, Y., 2008. Relationship between trends in temperature extremes and elevation in the eastern and central Tibetan Plateau, 19612005. Geophysical Research Letters 35(4): 1-7.

83. You, Q., Ren, G.Y., Zhang, Y.Q., Ren, Y.Y., Sun, X.B., Zhan, Y.J., Shrestha, A.B. and Krishnan, R., 2017. An overview of studies of observed climate change in the Hindu Kush Himalayan (HKH) region. Advances in Climate Change Research 8(3): $141-147$.

84. Zhang, X., Alexander, L., Hergerl, G.C., Jones, P., Tank, A.K., Peterson, T.C., Trewin, B. and Zwiers, F.W., 2011. Indices for monitoring changes in extremes based on daily temperature and precipitation data. WIREs Clim. Change, 2 (6): 851-870.

85. Zhou, J., Jumei Huang, J., 2020. Changes of Extreme Temperature and Its Influencing Factors in Shiyang River Basin, Northwest China, Atmosphere, 11, 1171; doi:10.3390/atmos11111171 


\section{Supplementary Files}

This is a list of supplementary files associated with this preprint. Click to download.

- Supplymaterial20092021.docx 